\title{
Training Individuals in Function-Based Behavior Intervention Plans Using Modeling, Rehearsal, and Self-Monitoring
}

Aimee F. Giles

West Virginia University

Follow this and additional works at: https://researchrepository.wvu.edu/etd

\section{Recommended Citation}

Giles, Aimee F., "Training Individuals in Function-Based Behavior Intervention Plans Using Modeling, Rehearsal, and Self-Monitoring" (2012). Graduate Theses, Dissertations, and Problem Reports. 261. https://researchrepository.wvu.edu/etd/261

This Dissertation is protected by copyright and/or related rights. It has been brought to you by the The Research Repository @ WVU with permission from the rights-holder(s). You are free to use this Dissertation in any way that is permitted by the copyright and related rights legislation that applies to your use. For other uses you must obtain permission from the rights-holder(s) directly, unless additional rights are indicated by a Creative Commons license in the record and/ or on the work itself. This Dissertation has been accepted for inclusion in WVU Graduate Theses, Dissertations, and Problem Reports collection by an authorized administrator of The Research Repository @ WVU.

For more information, please contact researchrepository@mail.wvu.edu. 
Training Individuals in Function-Based Behavior Intervention Plans Using Modeling, Rehearsal, and Self-Monitoring

\author{
Aimee F. Giles \\ Dissertation submitted to the \\ Eberly College of Arts and Sciences \\ at West Virginia University \\ in partial fulfillment of the requirements \\ for the degree of \\ Doctorate of Philosophy \\ in \\ Psychology \\ Claire St. Peter, Ph.D., Chair \\ Michael Perone, Ph.D. \\ Elizabeth Kyonka, Ph.D. \\ Elisa Krackow, Ph.D. \\ Richard Walls, Ph.D. \\ Department of Psychology
}

Morgantown, West Virginia

2012

Keywords: Staff training; education; self-monitoring; behavior intervention plan 


\begin{abstract}
Training Individuals in Function-Based Behavior Intervention Plans Using Modeling, Rehearsal, and Self-Monitoring
\end{abstract}

\title{
Aimee F. Giles
}

Behavior intervention plans based on the function of problem behavior are more likely to be effective than non-function-based plans. However, plans developed by teachers often do not address behavior function. In addition to ensuring that teachers can write function-based behavior intervention plans, it is also important to ensure plans are implemented with a sufficient degree of fidelity. The purpose of the present study was to evaluate a multi-component training package to train teachers to write function-based behavior intervention plans and to accurately implement differential reinforcement of alternative behavior for escape-maintained problem behavior. Twenty public school teachers of children with emotional and behavior disorders participated in a $7 \mathrm{hr}$ training. The training package consisted of video-modeling, didactic instructions, self-monitoring, and rehearsal. Data were collected using the Behavior Support Plan Qualitative Evaluation Guide on the quality of written plans produced by teachers during the training. Experimenter-developed treatment integrity checklists were used to collect data on the accuracy with which differential reinforcement of alternative behavior was implemented during role-plays. A pretest/posttest control group design was used. Statistical and visual analysis indicated increases in the quality of the written behavior plans and in the accuracy with which they implemented differential reinforcement of alternative behavior. 


\section{Acknowledgements}

I would like to thank Claire St. Peter, Mike Perone, Elizabeth Kyonka, Elisa Krackow, and Richard Walls for serving on my dissertation committee and for their valuable input in preparing this manuscript. I would especially like to thank Claire St. Peter for serving as the chair of my committee and for her contributions to this manuscript. I would also like to thank Sacha Pence, Shana Bailey, Ezra Hall, William Reilly, and Christopher Krebs for their help as trainers.

Finally, I would like to thank Jennie Cox, Kara Samaj, Tonya Marstellar, and Gretchen Poffenbarger for their help with data collection. 
Table of Contents

Acknowledgements iii

Table of Contents iv

List of Tables vi

List of Figures vii

Introduction 1

FBA ___ 2

The Importance of Linking BIP to FBA Results ___ 4

Training Individuals to Write Function-Based BIPs __ 8

Implementing Function-Based BIPs ___ 11

Self-Monitoring as a Training Tool ___ 14

Purpose _ 15

Method __ 16

Participants and Settings __ 16

Training Format and Experimental Design __ 17

Procedures _ـ 19

BIP-Writing Skills Probe _ـ 19

DRA Skills Probe _ 19

BIP-Writing Training _ 20

$D R A$ Training _ 21

Training Rating Profile (TRP-15) __ 22

Response Measurement and Interobserver Agreement __ 22

Hypotheses and Data Analyses ___ 24

Results _ 25

Discussion __ 30

References __ 38

Appendix A 52

Appendix B _ 55

Appendix C_ 58

Appendix D _ 59

Appendix E_ 60 
Appendix F_ 64

Appendix G_ 65 


\section{List of Tables}

Table 1: Descriptions and reasons for including the six concepts of PBS planning in the BSP $\mathrm{QE}$

Table 2: Participant demographic data 44

Table 3: Summary of participants' responses on the TRP-15 45 


\section{List of Figures}

Figure 1: Schematic depicting the training schedule. 46

Figure 2: Scores on the BSP-QE as a function of skill probe. The top panel depicts the data for the Group B and the bottom panel depicts the data for the Group A. Each data point depicts the data for a single participant. The bars depict the mean group performance at each skills probe. Stars indicate significance at the $p<.05$ level. Error bars indicate one standard deviation. 47

Figure 3: BSP-QE scores during Skills Probe 1, 2 and 3 for the Group B and Group A. Group B is depicted by the closed symbols and Group A is depicted by the open symbols. Error bars indicate one standard deviation.

Figure 4: Number of BIPs within each quality category prior to training (black bars) and following training (gray bars). 49

Figure 5: Accuracy scores for DRA implementation as a function of skill probe. The top panel depicts the data for the Group A and the bottom panel depicts the data for the Group B. Each data point depicts the data for a single participant. Stars indicate significance at the $p<.05$ level. The bars depict the mean group performance at each skills probe. Error bars indicate one standard deviation. 50

Figure 6: Accuracy scores during Skills Probe 1, 2 and 3 for the Group B and Group A. Group $\mathrm{B}$ is depicted by the closed symbols and Group A is depicted by the open symbols. Error bars indicate one standard deviation. 
Training Individuals in Function-Based Behavior Intervention Plans

Problem behavior in schools interrupts instruction and negatively impacts learning. These negative impacts occur in at least two ways (Wehby, Lane, \& Falk, 2003). First, problem behavior reduces instructional time while the teacher responds to the challenging behavior. For example, if students engage in disruptive behavior during math instruction, the teacher may need to deliver reprimands or prompt students to remain on task, thus postponing delivery of math instruction. Second, problem behavior may influence how the teacher interacts with the student, including the quality and duration of instruction delivered to that student. For example, if a student frequently engages in challenging behavior when presented with difficult math problems, the teacher may present easier problems to avoid challenging behavior. Both of these situations decrease instructional time or quality, resulting in less learning. Disrupted instruction may be especially detrimental for students with disabilities because those students are often already behind their same-age peers academically and need to learn more in less time to catch up with their peers.

Federal legislation has mandated that schools develop strategies to assess and manage problem behavior whenever a student's behavior impedes learning, a student's current behavioral goals are not sufficient to address problem behavior, a student with a disability is considered for expulsion, or when a student is placed involuntarily in a more restrictive placement (e.g., separate classroom or school) due to problem behavior (Individuals with Disabilities Education Act, 2004). First, a functional behavior assessment (FBA) is conducted to identify the conditions that are maintaining and supporting the occurrence of problem behavior. Behavior intervention plans (BIPs) are developed following the FBA to outline the strategies for managing problem behavior. 
The FBA and BIP processes are associated with high-stakes outcomes. For example, a student who engages in challenging behavior in the general education classroom may be moved to a more restrictive placement such as a separate classroom or a special school if problem behavior cannot be effectively managed. It is important to implement empirically identified best practices for assessing and managing problem behavior so that students can remain in the leastrestrictive, appropriate placement. Because of these high-stakes, it is imperative that teachers, who are integral to the FBA and BIP processes, are trained in best practice for assessing and managing challenging behavior.

The FBA and BIP processes mandated by law have been evaluated within the behavioranalytic literature. The current literature suggests that not only do individuals need to be trained in how to interpret an FBA and write a BIP, but individuals must also be trained how to implement procedures outlined in the BIP. To review the process of addressing problem behavior in schools, each of these components (FBAs, BIPs, and training) will be discussed separately. First, literature discussing the FBA process will be briefly described. Second, a review of BIP and specifically, the use of function-based BIPs will be presented. Finally, the empirical support for training individuals to write and implement a function-based BIP will be described.

\section{FBA}

An FBA is a process to determine the environmental variables that reinforce problem behavior. Functional behavior assessments are completed by teams of school professionals (teachers, administrators, psychologists) who observe students and conduct interviews to gather data about the student and the problem behavior. The results of the FBA are used to develop an intervention plan to address the problem behavior (a BIP). Although the law does not mandate a procedure, the FBA process generally involves interviewing teachers or other professionals who 
work with the child to identify the problem behavior and the situations in which problem behavior is likely to occur. Direct observations of the problem behavior are also conducted to identify the relevant antecedents that precede and the consequences that routinely follow problem behavior (Scott, Anderson, \& Spaulding, 2008; Sugai, Lewis-Palmer, \& Hagan-Burk 1999-2000).

The information gathered during the FBA process is used to develop a BIP. For example, an FBA might identify that the problem behavior was more likely to occur during math class and that the most common consequence following problem behavior was the teacher providing the student with easier math problems. These results suggest that behavior may be reinforced by escape from difficult academic demands. The resulting BIP would identify strategies to decrease problem behavior and increase appropriate behavior during class periods associated with difficult academic demands.

Another way to describe an FBA is that it identifies the potential function of problem behavior. Hanley, Iwata, and McCord (2003) describe behavior function loosely as the purpose a behavior serves for the individual. For example, problem behavior may result in a child gaining access to a preferred toy or escaping from a difficult academic task. When identifying the function of problem behavior, the focus is on pinpointing the environmental events that reinforce behavior.

Common functions of problem behavior include access to attention, access to tangible items, and escape from demands (Hanley et al., 2003). When problem behavior is identified as having an attention function, the behavior is reinforced by some form of social praise or disapproval. For example, a child may engage in head hitting when a parent is occupied with another task (cooking dinner). When the child hits his head, the parent scolds the child. Attention 
in this example, even in the form of a reprimand, may function as a reinforcer for the child's head hitting. Another form of positive reinforcement is access to tangible items. When problem behavior is identified as having a tangible function, the behavior is reinforced by accessing a preferred item or activity. For example, a child may hit his peer to access the toy with which the peer is playing.

The most commonly identified function of problem behavior is escape (Hanley et al., 2003). When problem behavior is identified as having an escape function, the behavior is reinforced by removal or avoidance of an aversive situation. For example, if a student is sent to time-out during reading for ripping academic materials and the behavior increases or persists at the same level, behavior may be maintained by escape. This example highlights the importance of function-based interventions in schools. Time-out is a common classroom intervention for problem behavior. When behavior is reinforced by attention, time-out is an effective, functionbased intervention because it eliminates the delivery of attention following problem behavior. However, when the functional reinforcer for problem behavior is escape, time-out may result in maintenance or worsening of problem behavior because the student escapes the difficult academic task during the time-out period (e.g., Filter \& Horner, 2009). In the previous example, the child escapes or avoids reading when he is sent to time-out.

\section{The Importance of Linking BIP to FBA Results}

Only $1 \%$ to $5 \%$ of students in a school require function-based BIPs; however, those students encompass $50 \%$ of the office referrals addressed by administrators and teachers (Sugai, Sprague, Horner, \& Walker, 2000). These students may require substantial amounts of the teachers' and administrators' time and resources. For this reason, emphasis should be placed on developing effective BIPs. 
Typically, teachers develop a BIP after the completion of the FBA process (once the maintaining reinforcer has been identified) because BIPs based on the results of the FBA are more likely to be effective than plans using arbitrary reinforcers. Function-based BIPs use the reinforcer that maintains problem behavior and can prevent periods of unintentional deprivation or restriction of the reinforcer that may have resulted in the occurrence of problem behavior (Filter \& Horner, 2009; Ingram, Lewis-Palmer, \& Sugai, 2005; Newcomer \& Lewis, 2004).

Behavior intervention plans that are based on the function of problem behavior include explicit strategies to teach the child appropriate ways to access the reinforcers currently maintaining problem behavior. In addition, function-based BIPs often specify procedures to ensure that reinforcers are no longer delivered following problem behavior (extinction). An example of a function-based intervention for a student who engages in swearing to escape gym class may include teaching the student to ask to go for a walk in the hallway during gym and prompting the student to remain in the gym following instances of swearing. This BIP provides the functional reinforcer for an alternative response (asking for a walk) and withholds that reinforcer when the student engages in problem behavior.

Filter and Horner (2009) compared function-based interventions and non-function-based interventions for two elementary-aged students with emotional disabilities. Following a functional analysis that identified escape as the function of problem behavior, a function-based and a non-function-based intervention was evaluated for each participant. For one participant, the function-based intervention involved decreasing the difficulty of academic activities. The nonfunction-based intervention was time-out. For the second participant, the function-based intervention involved teaching the student to request additional instructional help from a teacher and access to easier academic tasks. The teacher provided supporting statements (e.g., "You can 
do this, I know you can”) to the student contingent on occurrences of problem behavior for the non-function-based intervention. Although the non-function-based interventions for both participants were common interventions used by teachers, they were ineffective at reducing problem behavior. For both participants, less problem behavior and more task engagement occurred during the function-based intervention. These results suggest that linking intervention to the results of an FBA may be the best strategy for decreasing challenging behavior when common classroom procedures are ineffective.

One of the most common function-based interventions for treating problem behavior is differential reinforcement of alternative behavior (DRA; Tiger, Hanley, \& Bruzek, 2008). Differential reinforcement of alternative behavior involves teaching a participant an alternative behavior that results in delivery of the functional reinforcer. In addition, problem behavior is usually placed on extinction, meaning that the functional reinforcer is withheld following instances of problem behavior. Differential reinforcement of alternative behavior is effective across many topographies and functions of problem behavior (Carr \& Durand, 1985; Hanley, Iwata, \& Thompson, 2001; Lalli, Casey, \& Kates, 1995; Winborn, Wacker, Richman, Asmus, \& Geier, 2002). One benefit of DRA is that it explicitly teaches an alternative replacement behavior, which is a requirement of the Individuals with Disabilities Education Act (2004). Although other function-based interventions (such as differential reinforcement of other behavior; Hammond, Iwata, Fritz, \& Dempsey, 2011) effectively reduce problem behavior, DRA is the only common differential reinforcement intervention that explicitly requires a specific alternative response.

Teachers are able to use DRA in typical classrooms to reduce problem behavior (Codding, Feinberg, Dunn, \& Pace, 2005; DiGennaro, Martens, \& Kleinmann, 2007; Lalli, 
Browder, Mace, \& Brown, 1993). For example, DiGennaro et al. (2007) trained teachers to implement DRA to decrease off-task behavior maintained by escape for four special education students. During DRA, the teacher provided the student with a token following compliance with academic instructions. When the student earned five tokens, he was provided a break from work. Differential reinforcement of alternative behavior decreased off-task behavior for three of the four students.

Codding et al. (2005) also trained teachers to implement behavior intervention plans that included a DRA component with students. Teachers were initially trained to implement the BIP in a one-to-one context with a trainer using modeling and prompting. Initial training lasted until the teachers verbally reported that they could implement the BIP correctly. Then, data were collected by observers who recorded the teachers' accurate implementation of the BIP while they worked with students. Feedback was provided following the initial training when accurate implementation of the BIP was not occurring at high levels or performance was deteriorating. Feedback was sufficient to increase accurate BIP implementation to acceptable levels for all teachers.

Teachers may be trained to implement function-based interventions such as DRA, but teachers are often responsible for developing and writing BIPs as well. Developing functionbased BIPs such as DRA is considered best practice; however, teacher-produced BIPs often do not address the function of the problem behavior identified in the FBA (Cook et al., 2007; Van Acker, Boreson, Gable, \& Potterton, 2005). For example, Van Acker et al. (2005) evaluated the FBAs and BIPs written by teachers. Seventy-one BIPs were submitted from school districts across the state of Wisconsin. Behavior intervention plans were evaluated along several dimensions, including whether the submitted BIP addressed the reported function of problem 
behavior identified by the FBA. Only 35\% of the BIPs indicated how the function of problem behavior was addressed by the written plan. When comparing the quality of the BIP with the training level of the team members, BIPs produced by teams that included at least one member who had advanced training in applied behavior analysis or attended a two-day intensive workshop on the FBA/BIP process produced better BIPs.

Behavior intervention plans that are not linked to functional assessment are problematic for at least three reasons. First, federal legislation mandates that BIPs be developed based on the results of an FBA (Individuals with Disabilities Education Act, 2004). Second, BIPs based on the function of problem behavior are more likely to be effective (e.g., Filter \& Horner, 2009). Third, if function-based BIPs are more effective, they may be less resource-intensive because teachers and school staff will not need to devote as much time to managing challenging behavior. For these reasons, it is important to identify strategies for training individuals to link the results of FBAs to BIPs.

\section{Training Individuals to Write Function-Based BIPs}

The training and experience of teachers writing BIPs may impact the extent to which the results of behavior assessment and intervention plans are linked. Because BIPs are written products, it may be difficult to evaluate the quality of BIPs without a formal rubric or guide. The Behavior Support Plan Qualitative Support Evaluation Guide (BSP-QE) is a qualitative scoring rubric to evaluate the content of BIPs (Browning-Wright, Saren, \& Mayer, 2003; Kraemer, Cook, Browning-Wright, Mayer, \& Wallace, 2008). The BSP-QE evaluates six empirically supported concepts of effective behavior intervention planning: behavioral function, situational specificity, behavior change, reinforcement tactics, reactive strategies, and team coordination and 
communication. All of these concepts are operationally defined (see Table 1, reproduced from Browning-Wright et al., 2003, for operational definitions of each concept).

A scoring rubric based on these concepts was developed that is comprised of 12 different components of a BIP. Each of the 12 components is operationally defined and scored based on a three-point Likert scale with scores ranging from 0 to 2 . The scores on the 12 different components are summed to provide a global score. Behavior plans fall within four different quality categories (weak, underdeveloped, good, and superior) based on the global scores. The BSP-QE has adequate reliability, as established by item-total correlations, internal consistency, and interrater reliability statistics (Browning-Wright, Mayer, Cook, Crews, Kraemer, \& Gale, 2007; Cook et al. 2007).

To evaluate the role experience plays into writing function-based BIPs, Cook et al. (2007) compared the quality of behavior plans developed by teams that included a team member with specialized training in writing BIPs (advanced teams) to BIPs developed by teams without substantial training (typical teams). Participants in the advanced-teams group had completed 6 hrs of training on positive behavior supports, an average of two classes in applied behavior analysis, and had attended approximately 10 trainings on behavior management. Demographic data and level of experience of the typical teams were not available.

The BIPs written by the advanced teams received higher scores on the BSP-QE than did BIPs written by the typical teams. Sixty-five percent of the BIPs written by school staff with advanced training fell within the "good" or "superior" categories of the BSP-QE. Conversely, only $11 \%$ of the BIPs written by the typical teams fell within the "good" or "superior" categories. In addition, plans written by the typical teams often did not identify an environmental function for problem behavior (Cook et al. 2007). Although this study was correlational rather 
than experimental, the results suggest that teachers who receive advanced training create acceptable and complete BIPs. However, the typical teacher in a school may not have the training necessary to create quality interventions.

Although highly trained individuals can produce effective BIPs, it may not be feasible for school districts to hire highly qualified consultants to conduct FBAs and develop BIPs for all students who require them. An alternative would be to identify personnel already in the schools (e.g., teachers and administrators) who can be trained in effective function-based intervention planning (Scott, Liaupsin, Nelson, \& McIntyre, 2005). Because a typical teacher may not have extensive training in the FBA or BIP processes (e.g. Cook et al., 2007; Van Acker et al., 2005), additional research on effective training strategies is warranted.

One method to improve teacher-developed BIPs is to train teachers to use evaluation tools like the BSP-QE. Browning-Wright et al. (2007) assessed the extent to which this strategy improved teacher-developed intervention plans. Initially, participants received didactic training that reviewed several concepts related to FBA and BIP development. The BIPs submitted by participants following the initial training were identified as being weak or underdeveloped and were not based on the function of behavior. During a second training, participants received 6 hours of training on how to use the BSP-QE to evaluate written BIPs. Not all participants in the second training participated in the first training.

During the second training, the trainer reviewed the six key concepts of the BSP-QE, provided instruction on scoring plans with the BSP-QE (for $3 \mathrm{hr}$ ) and gave teachers opportunities to practice writing and scoring hypothetical BIPs (for $3 \mathrm{hr}$ ). The BIPs submitted by the teachers following the training on the BSP-QE received significantly higher BSP-QE scores than the previous plans submitted after the first didactic training. However, it is unclear if the BIPs 
following training on the BSP-QE were better because the participants were trained to use the scoring tool or because some participants had been exposed to additional training.

To address this potential confound, Kraemer et al. (2008) replicated the procedures described by Browning-Wright et al. (2007) with graduate students enrolled in special education courses. Participants submitted a sample BIP prior to participating in the training. These plans were compared to plans completed by the participants after the training. Plans completed after training on the BSP-QE were significantly better than the previously submitted plans. Taken together, the results of Kraemer et al. (2008) and Browning-Wright et al. (2007) suggest that training individuals to evaluate BIPs using the BSP-QE increases BIP quality. However, the participants in both studies may have been more experienced in function-based interventions than average teachers. The participants in Browning-Wright et al. were considered leaders in conducting FBAs and developing BIPs in their school districts. In addition, $86 \%$ of the participants in Kraemer et al. had between one and three graduate-level courses in applied behavior analysis or functional assessment. It is unclear if a brief training using the BSP-QE would yield similar results with participants with less experience in function-based BIP development.

\section{Implementing Function-Based BIPs}

Although training teachers to write function-based BIPs is an important first step, training the skills necessary to write intervention plans does not mean that teachers will be able to implement the interventions consistently and as written (in other words, with an acceptable level of treatment integrity). Participant knowledge about behavioral procedures, such as functional analysis, does not translate into accurate implementation of those procedures. Additional training is often necessary for the participants to demonstrate an acceptable level of accurate functional 
analysis implementation (Moore et al., 2002; Moore \& Fisher, 2007). Similarly, writing a BIP is a way to demonstrate knowledge about that intervention; however, it does not mean that the participant will be able to accurately implement the intervention.

Higher degrees of treatment integrity are associated with better treatment outcomes (e.g., St. Peter Pipkin, Vollmer, \& Sloman, 2010; Vollmer, Sloman, \& St. Peter Pipkin, 2008). In addition, interventions that are implemented with low levels of treatment integrity cannot be evaluated to determine if they are efficacious. If an intervention is implemented poorly, it is impossible to determine if the intervention is ineffective or if the perceived ineffectiveness of the intervention is due to it not being implemented as prescribed. When high-stakes decisions such as school placement are being considered, it is especially important that treatment integrity is acceptable to evaluate whether a BIP is effective.

Teachers must be directly taught the skills necessary to implement BIPs with integrity. One way to improve the integrity with which teachers implement function-based interventions is through behavioral skills training (DiGennarro et al., 2007; DiGennaro-Reed, Codding, Catania, \& Maguire, 2010; Noell, Duhon, Gatti, \& Connell, 2002). Behavioral skills training generally involves four components: didactic instruction, modeling, rehearsal, and performance feedback (e.g., DiGennarro et al., 2007). During didactic instruction, the intervention is described in a lecture-based format. Following didactic instruction, the trainer models how to perform the skill. During the rehearsal phase, the trainer and trainee role-play so that the trainee can practice the skill with the trainer. For example, if training DRA, the trainer may play the role of a child who engages in problem behavior. The trainee would play the role of the teacher implementing the DRA procedure. During feedback, which may occur during rehearsal and following mastery to 
assist with skill maintenance, the trainer outlines the components of the skill that the participants performed accurately and inaccurately.

Behavioral skills training is an effective way to train teachers to implement BIPs when implemented with favorable trainer-trainee ratios. For example, DiGennaro et al. (2007) used a behavior skills training package to train four special education teachers how to implement function-based BIPs. Teachers were trained one-on-one with a trainer on a function-based BIP using modeling, rehearsal, and feedback. All participants mastered the BIP during the initial behavior skills training. Following the training, data were collected on how accurately teachers independently implemented the behavior plan. Because accurate behavior plan implementation was low following training, feedback was necessary to improve accurate implementation to acceptable levels. Similarly, Noell et al. (2002) successfully used behavioral skills training involving modeling, rehearsal and feedback to train four general education teachers to implement BIPs.

One potential limitation is that the trainings described by Noell et al. (2002) and DiGennaro et al. (2007) were conducted in a one-to-one context. A potential barrier to implementing behavioral skills training with teachers across a district is that school districts may expect that the training be conducted in a resource-efficient large-group format. Because inservice training provided to teachers typically occurs in a large-group format, one-to-one trainings may be viewed as an inefficient use of training resources by school administration. Additionally, it may not be feasible to have a sufficient number of trainers to conduct one-to-one training with a large group of school professionals. Although didactic instruction alone may seem like the best alternative when behavioral skills training is not feasible, this is not an effective way to train BIP planning (Browning-Wright et al., 2003). Identifying how to modify 
behavioral skills training to a large-group format is an important next step toward broader dissemination of evidence-based practices.

\section{Self-Monitoring as a Training Tool}

One method for bridging the gap between traditional 1:1 behavioral skills training packages and a larger group training would be to include self-monitoring in the training package. Including self-monitoring could maintain key characteristics of behavioral skills training such as role-playing and feedback. Participants who are provided with materials to monitor the accuracy of their own performance could rehearse with peers instead of a trainer. One or two trainers could circulate the room and provide feedback to participants and answer questions.

Self-monitoring checklists could be used during large-group initial trainings to provide feedback to participants on how well they implement an intervention. For example, following initial didactic instruction and modeling of a BIP, participants could be paired with each other. One or two trainers could distribute self-monitoring sheets that contain explicit descriptions of how the intervention should be implemented and operational definitions of each component of the intervention. Trainers could demonstrate how participants should use the self-monitoring sheets to evaluate their own implementation of the intervention while they role-play with a peer. The trainer could then circulate the room to answer questions and provide feedback to the entire group. The participants could potentially receive feedback from the self-monitoring form and their peer in addition to the trainer. Thus, the addition of self-monitoring during initial training could remove the need for each participant to individually role-play with a trainer. By having trainees role-playing with each other, fewer trainers are necessary, making it possible to train more people simultaneously. 
Although self-monitoring has not been evaluated as a component in initial behavior intervention training, it has been used following an initial training to maintain accurate implementation of a BIP. Plavnik, Ferreri, and Maupin (2010) initially trained participants to implement a token economy (a type of BIP) using a behavioral skills training package that consisted of 1:1 didactic instruction, modeling, and role play. All participants mastered the BIP implementation during the initial training, but did not consistently implement the plan accurately in their classrooms after training. Participants were then provided with a self-monitoring checklist that described how the token economy should be implemented and were instructed to collect data on their performance. Self-monitoring increased accurate behavior plan implementation compared to execution of the token economy without any feedback. In addition, the self-monitoring checklists allowed participants to monitor their own behavior and receive feedback in the absence of the trainer.

Similar to using checklists during role-playing, the BSP-QE may also function as a form of self-monitoring. When participants evaluate the quality of their written BIP using the BSPQE, they compare their written products to operational definitions of different components of quality plans. Participants may then evaluate how well their plan meets these criteria and make revisions as necessary.

\section{Purpose}

Teachers can be trained to write function-based intervention plans during relatively brief, larger-group trainings (6 hr). However, the participants in existing research had advanced training in either function-based interventions or behavior analysis prior to the training (several advanced courses in applied behavior analysis and several weeks of prior training in FBA and 
BIP planning). It is unclear if the effectiveness of these training procedures will generalize to individuals with less advanced training.

In addition to writing quality plans, teachers can be trained to implement function-based interventions. However, training was initially conducted in a 1:1 trainer-trainee ratio, limiting how efficiently people can be trained. Self-monitoring may be a tool to bridge the gap to largergroup training.

Finally, although individuals can be trained to write and implement function-based BIPs separately, no one has evaluated a comprehensive training package to train both skills. Thus, the purpose of the present study was to evaluate a training package involving didactic instruction, self-monitoring using the BSP-QE, and feedback to teach individuals without extensive training in behavior intervention planning to write function-based BIPs and to accurately implement a DRA for escape-maintained behavior.

\section{Method}

\section{Participants and Settings}

Twenty-two public-school special educators participated as part of an in-service training mandated by their school district. The participants comprised all special education teachers for children with emotional and behavior disorders in the school district. Nine teachers were male and 13 were female. Data for two participants were excluded from the study because they reported having more than one graduate-level course in Applied Behavior Analysis. In addition, one male participant left the training prior to completing any posttests, and his data were excluded from data analyses.

Table 2 depicts the participants' demographic data. The average age for participants was 38 years old (range, 24-57 years) and participants averaged 10 years of experience (range, 1-33 
years). All teachers were certified to teach special education and were either currently teaching students with BIPs or had done so in the past. Participants' self-reported experience with writing and implementing BIP varied from no experience to over twenty years of experience writing BIPs for a variety of students.

Informed consent was not required to be obtained from participants because the training was part of a mandatory in-service. Participants were provided with a letter stating that the researchers would like to use the data collected during the training as part of a research project. In addition, participants were informed that it would not be possible to link any of the data obtained from the study back to individual participants. Participants could revoke their consent to allow their data to be included in the project at any time. No participants requested that their data be excluded from the study.

The training was conducted in two elementary school classrooms across a 7-hr day when no students were present. The classrooms contained desks, chairs, and a computer with a projector for displaying training videos or slides. In addition, the classroom used for training DRA implementation contained four areas for the participants to role-play with trainers during pretests and posttests. Each of the role-play areas was in a separate corner of the classroom and consisted of a desk and two chairs. A box containing a timer, math worksheets, pencils, and a sheet specifying operational definitions of the target behavior were also present. In addition, a video camera and tripod were placed at each of these four areas to record role-play sessions.

\section{Training Format and Experimental Design}

At the start of the training day, participants were given a notebook of training materials. Although notebooks were designated as being for "Group A" or "Group B," they contained identical training materials. The notebooks were presorted so that group labels alternated and 
notebooks were handed out to participants in that order based on when participants arrived. After excluding the data for the two participants with graduate training in Applied Behavior Analysis and an additional participant who did not complete any posttest measures, there were 10 participants in Group A and nine participants in Group B.

The training day was organized into blocks of time in which participants engaged in skillacquisition activities or completed skills probes (see Figure 1). Skill acquisition activities included direct instruction and guided practice on the BIP and DRA skills. Skills probes required participants to design mock BIPs and conduct DRA sessions with a confederate.

Skills Probe 1 was conducted during the first hour of the training day to establish a baseline of BIP and DRA skills. After completing Skills Probe 1, training was conducted on either implementing DRA (for Group A) or writing BIPs (for Group B). Following the training, all participants completed Skills Probe 2, which included an identical battery of assessments to those presented in Skills Probe 1. Participants were then provided a 1-hr lunch break. After lunch, a second training was conducted on either writing BIPs (Group A) or implementing DRA (Group B), followed by a final series of assessments (Skills Probe 3) that were identical to the assessments completed in the morning.

A modified pretest-posttest control group design (Campbell \& Stanley, 1963) was used to assess functional relations between training and assessment performance. In a traditional pretestposttest control group design, all participants are assigned to either an experimental group or a control group. A pretest measure is collected for all participants, after which the experimental group is exposed to an intervention. Following the intervention for the experimental group, a posttest measure is collected for both groups. Within the modified design used in the present study, all participants participated in both experimental and control groups. After Skills Probe 1, 
Group A served as the treatment group for DRA training whilst Group B served as the control group. With regard to BIP training, Group B served as the treatment group whilst Group A served as the control group. After Skills Probe 2, training topics switched for each group, such that both groups were eventually exposed to both training protocols (i.e., BIP and DRA). This allowed examination of the degree to which the order of training might have affected performance on Skills Probe 3 and ensured that all participants benefitted from participating in both trainings.

\section{Procedures}

BIP-Writing Skills Probe. During the BIP-writing skills probe, the experimenter provided each participant with a hypothetical FBA and a structured outline form for the BIP (see Appendices A and B). Each participant was provided with the same hypothetical FBA during each probe to ensure that differences in the quality of the written BIPs were not due to differences in the FBA results. The experimenter instructed participants to try their best to complete the structured BIP form based on the FBA summary statement. When participants asked questions, they were instructed to try their best. Participants were not encouraged to work with each other, but the trainer did not stop participants from conversing with each other. Participants were provided with up to 30 minutes to complete the BIP.

DRA Skills Probe. DRA skills probes were conducted in a one-to-one data-collector-toparticipant role-play context, during which the data collector acted a student and the participant acted as a teacher implementing DRA. Four trained data collectors simultaneously conducted pretest sessions with participants; however, data collector-trainee dyads were spaced throughout the room to minimize interference. Before each probe, the data collector provided the participant with operational definitions of problem behavior and appropriate behavior, a timer, pencils, and 
math worksheets. The data collector asked the participant to demonstrate what she knew about conducting DRA. The data collector volunteered to role-play with the participant and play the role of the student. The participant was prompted to use the academic materials to simulate an instructional context.

Data collectors were instructed to attempt to make probe sessions 5-min in duration, but obtained session duration depended on how the participant responded during the session. Probe sessions averaged 4.9-min in duration (range, 2.5 to $9 \mathrm{~min}$ ). While waiting to complete the first probe with a data collector during Skills Probe 1, the participants completed a demographic questionnaire (see Appendix $\mathrm{C}$ for the questionnaire).

During each pretest role-play, the data collector engaged in five instances of problem behavior and five instances of appropriate behavior according to a predetermined script (see Appendix D). If the participant asked questions about the intervention or refused to attempt or complete the intervention, the data collector prompted the participant to try their best one time. If the participant continued to refuse after this prompt, accuracy for the pretest was recorded as $0 \%$ (for participants who refused to complete the probe altogether) or accuracy was only calculated for the components completed (for participants who refused to finish the probe).

BIP-Writing Training. A training protocol was developed prior to the training to ensure that the same content was provided across both training groups. The didactic instruction component of the training was presented with accompanying power point slides (see Appendix E) and consisted of the following components: a description of behavior function and functionbased intervention, a description of DRA, hypothetical examples of DRA for escape-maintained behavior, a review of the BSP-QE, and examples of how the BSP-QE could be used to evaluate 
DRA for escape-maintained behavior. When reviewing the BSP-QE, participants were instructed to following along with the BSP-QE in their training manuals.

Following the didactic instruction component of the training, participants were provided with hypothetical results of an FBA, a structured BIP form, and a copy of the BSP-QE guide and scoring sheet. The hypothetical FBA results were different from the results provided to the participant during the pretest but still described escape-maintained problem behavior. Due to limitations with time, the participants worked as a group to fill out the hypothetical BIP using the BSP-QE as a guide. The trainer answered any questions asked by the participants.

DRA Training. The DRA training was conducted in a large-group format with one trainer. At the start of the training, the trainer showed a 25-min video demonstrating DRA being implemented for escape-maintained problem behavior. The experimenter-developed video began with a sample of DRA for escape-maintained problem behavior being conducted in a classroom for elementary students. The video the highlighted five different components of DRA implementation with corresponding video examples: providing a break following compliance, pairing praise with break delivery, ignoring problem behavior, and withholding reinforcement if appropriate behavior occurs at the same time as problem behavior. The final part of the video consisted of examples of DRA being implemented with high school students. Text overlay was used to illustrate each of the five components of DRA implementation after they were shown on the video. After the video, participants were provided with the opportunity to ask the trainer questions about DRA.

After the didactic component of the training, the trainer distributed operational definitions for problem behavior, appropriate behavior, and self-monitoring forms for DRA (see Appendix F for self-monitoring form). The trainer described each component on the self-monitoring form 
and how to use the form to record accurate DRA implementation. Participants were prompted to practice conducting DRA with their partner and take turns being the teacher and student. Participants were also instructed to record data on how accurately they implemented DRA using the self-monitoring forms. The experimenter did not provide the participants with scripts for practice, but instructed participants who were acting as the student to engage in at least three instances appropriate and three instances of inappropriate behavior during each role play.

The trainer circulated the room at this time to answer questions and provide feedback on how accurately the participants were performing DRA. Participants were instructed to continue to practice the skills until they felt they could perform DRA with at least $90 \%$ accuracy during the role play.

Training Rating Profile (TRP-15). The TRP-15 (see Appendix G) was administered to participants after they completed the DRA skills probe during Skills Probe 3. The TRP-15 is a modified version of the Intervention Rating Profile for Teachers (IRP-15), which evaluates the acceptability of different interventions (e.g., Witt, Martens, \& Elliott, 1984).The TRP-15 consists of 15 questions rating different aspects of the acceptability of the training on a Likert scale with a range of 1 (strongly disagree) to 6 (strongly agree). Higher scores are associated with more acceptable training procedures.

\section{Response Measurement and Interobserver Agreement}

The dependent variable for BIP writing was the percentage of components scored as correct on the BSP-QE. The BSP-QE is a reliable, valid, and qualitative scoring rubric to evaluate the content of BIPs (Browning-Wright et al., 2003; Kraemer et al., 2008). The BSP-QE evaluates six empirically supported concepts of effective behavior intervention planning: behavioral function, situational specificity, behavior change, reinforcement tactics, reactive 
strategies, and team coordination and communication. There are 12 different components that evaluate these six concepts and each component is operationally defined and scored on a threepoint scale (0-2).

Interobserver agreement was assessed by having a second, trained observer collect data independently from the written BIP sample. The secondary observer was blind to the condition from which the BIP had come (i.e., she was unaware if the person who had written the BIP had received any training). Prior to the experiment, observers were trained to score BIPs using the BSP-QE. Observers practiced scoring BIPs using the BSP-QE until both observers demonstrated at least $90 \%$ agreement across three consecutive BIPs.

Agreement data were collected for $63 \%$ of submitted BIPs. Agreement was calculated by comparing observer records and assessing observer agreement on the numerical score assigned to each component on a component-by-component basis. For example, if Observer 1 scored Component A: Problem Behavior with a 2 and Observer 2 also scored that component with a 2, then the observers would be in agreement for that component. If Observer 1 scored Component A: Problem Behavior with a 2 and Observer 2 scored that component with a 1, then the observers would be in disagreement for that component. The number of components with agreement were divided by the number of components with agreement plus disagreement and multiplied by 100 . Agreement averaged 94.3\% (range 84-100\%) for scoring participants BIPs using the BSP-QE.

The dependent variable for DRA was accurate delivery of consequences for appropriate and inappropriate behavior during the pretest and posttest role-play scenarios. Data were collected in vivo or from video on participants' accurate implementation of each of the six components of DRA, using data sheets identical to the self-monitoring forms distributed to participants (see Appendix F). For each component, the data collector recorded a tally mark if a 
component was performed accurately in the "correct" box or in the "incorrect" box if it was performed inaccurately for each opportunity to perform that skill. Opportunities where the participant responded accurately were summed across all components, divided by the total number of opportunities, and multiplied by 100 to obtain the percentage of overall accuracy for each participant.

Interobserver agreement was assessed by having a second, trained observer independently collect data across $30 \%$ of skills probe sessions. Data collectors were previously trained to collect in vivo treatment integrity data with at least $90 \%$ accuracy. Agreement was calculated by comparing observer responses for each component within the session. There were six DRA-related skills targeted during the training and the participant could have responded correctly or incorrectly for each skill (see Appendix F). Subsequently, there were 12 components assessed for IOA. Within each component the smaller number was divided by the larger number to create a proportion. For example, if Observer 1 recorded three instances where the participant correctly ignored problem behavior and Observer 2 recorded two instances, the resulting proportion would equal .66. The proportions for all 12 components were averaged and converted to a percentage for the entire session. Agreement for DRA averaged 92.3\% (range 81-100\%).

\section{Hypotheses and Data Analyses}

Hypothesis 1: Between-subject scores on the BSP-QE completed at Skills Probe 2 will be significantly higher for participants who have completed the BIP training than for participants who have not completed the training.

Hypothesis 2: Within-subject scores on the BSP-QE will be significantly higher following BIP training compared to the pretraining. 
Hypotheses 1 and 2 were evaluated using a 2 x 3 mixed-model analysis of variance (ANOVA). The mixed-model ANOVA compared scores on the BSP-QE during each skills probe. Training group (control or experimental) was a between-subjects factor and each skills probe (Skills Probe 1, 2, or 3) was a within-subjects factor.

Hypothesis 3: Between-subject accuracy scores for DRA during Skills Probe 2 will be significantly higher for participants who have completed the DRA training than for participants who have not completed the training.

Hypothesis 4: Within-subject accuracy scores for DRA will be significantly higher following DRA training compared to the pretraining.

Hypotheses 3 and 4 were evaluated using a 2 x 3 mixed-model ANOVA. The mixedmodel ANOVA compared accuracy percentages for DRA during each skills probe. Training group (control or experimental) was a between-subjects factor and each skills probe (Skills Probe 1,2 , or 3) was a within-subjects factor.

\section{Results}

\section{BIP Writing}

Overall, BSP-QE scores increased following the BIP-writing training. Figure 2 depicts the results of the BIP-writing training for all participants. The data in the top panel depict the results for participants in Group B, who were trained in BIP writing first. Data for only seven participants in Group B are reported because two participants did not complete any Skills Probes for BIP Writing. Higher BSP-QE scores during Skills Probe 2 than during Skills Probe 1 were observed for most participants in Group B. In addition, the increased BSP-QE scores were maintained during Skills Probe 3. Participants in Group A also demonstrated higher BSP-QE 
scores following training (Skills Probe 3) than BSP-QE scores observed during Skills Probes 1 and 2.

A 2 (group) x 3 (skills probe) mixed-model ANOVA was performed on participants' BSP-QE scores to evaluate the effects of the training on the quality of participant's written BIPs. Group was a between-subjects factor and the skills probe was the within-subjects factor. Mauchly's test indicated that the assumption of sphericity had been violated, $X^{2}(2)=6.08, p=$ .048 , therefore degrees of freedom were corrected using the Greenhouse-Geisser correction factor. There was a significant main effect of skills probe, $F(1.48,22.19)=17.94, p=.00$. Contrasts revealed that BSP-QE scores during Skills Probe $2(M=13.9, S D=6.1)$ and Skills Probe $3(M=16.4, S D=6.2)$ were significantly higher than scores on Skills Probe $1(M=10, S D$ $=5.5), p=.00$. There was not a significant main effect for group; BSP-QE scores were not significantly different for the experimental or control groups $F(1,15)=3.59, p=.078$.

There was a significant interaction effect between group and skills probe, $F(1.48,22.19)$ $=4.65, p<.029$, indicating that scores on the BSP-QE for each skills probe differed for participants in the two groups. To break down the interaction, contrasts were performed and revealed that scores on the BSP-QE were not significantly different for participants in the control or experimental group at Skills Probe 1 or Skills Probe 3, but were significantly different at Skills Probe $2, F(1,15)=18.48, p=.001$. Figure 3 depicts the interaction between group and skills probe. At Skills Probe 2, participants Group B had completed the BIP-writing training and the participants in the Group A had not. The BSP-QE scores for participants Group B were significantly higher than the scores for participants in Group A at Skills Probe 2.

Because one of the primary goals was to train participants to write function-based behavior intervention plans, the individual BIPs were evaluated to determine if increases in the 
BSP-QE scores were a function of participants writing function-based BIPs or if the scores increased because other aspects of the BIP improved (e.g., better operational definitions of the target behavior). Three components of the BSP-QE that deal specifically with behavior function include identifying the function of behavior, identifying a functionally equivalent replacement behavior, and identifying a reinforcer.

Identifying the function of behavior. This component of the BSP-QE directly evaluates if the BIP identifies and describes an environmental function of problem behavior. Prior to the BIP-writing training, 10 participants received a 0 or a 1 on the component related to identifying the function of behavior. The highest score possible was a 2. Following the training, 7 out of the 10 participants improved their score on that component meaning that the function of the problem behavior was described in the BIP. In addition, 4 of those participants improved their score on that component by two points (the maximum increase possible).

Identifying a functionally equivalent replacement behavior. For this component, participants needed to logically relate the replacement behavior to the function of target behavior. It was only possible to score a 0 or 2 on this component. Prior to the BIP-writing training, three participants scored a 2 and this component and 17 participants scored a 0. Following the training, 11 of the 17 participants improved their scores on this component, suggesting that BIPs were more likely to have a replacement behavior that matches the function of the target behavior.

Identifying a reinforcer. For this component, participants needed to identify a reinforcer to be used in the BIP. Because the BSP-QE evaluates if the resulting plan is designed to address the function of the problem behavior, participants should have identified a reinforcer to be used in the intervention that matched the reinforcer identified in the FBA (i.e., escape). For this 
component, participants could score a 0,1 , or 2 . Prior to training, 17 participants received a score of 0 or 1 on the component related to identifying a reinforcer. Following training 15 of the 17 participants improved their scores on this component by at least 1 point. Taken together, the increases in BSP-QE scores for these three components suggest that the overall increases in BIP quality following training were due, at least in part, to addressing the function of the target behavior in the BIP.

Overall quality of the BIP. Figure 4 depicts the categorical descriptions for the quality of participants' BIPs, based the score on the BSP-QE. Pretraining data were obtained at Skills Probe 1 and posttraining data were taken at Skills Probe 3. Behavior plans may fall within four different quality categories (weak, underdeveloped, good, and superior) based on the global scores. "Weak" and "underdeveloped" BIPs are less likely to be successful. Behavior intervention plans that fall within the "good" and "superior" categories are more likely to be successful. Prior to training, the majority of the BIPs fell within the "weak" and "underdeveloped" categories. None of the BIPs fell into the "superior" category. Following training, most of the BIPs fell into the "good" or "superior" categories suggesting that, over the group of participants, BIP quality improved.

\section{DRA Implementation}

Overall, accuracy when implementing DRA increased following the DRAimplementation training. Figure 5 depicts the results of the DRA-implementation training for all participants. The data in the top panel depict the results for participants in Group A who were trained in DRA implementation first. Higher accuracy scores were observed for most participants in Group A following training at Skills Probe 2 than at Skills Probe 1. The increased accuracy scores were maintained during Skills Probe 3. Participants in Group B also demonstrated higher 
accuracy scores following training (Skills Probe 3) than at Skills Probes 1 and 2. Overall, participants in both groups demonstrated improvements in DRA performance following training. A 2 (group) x 3 (skills probe) mixed-model ANOVA was performed on participants' DRA accuracy scores to evaluate the efficacy of the training on DRA implementation accuracy. Group was a between-subjects factor and the skills probe was the within-subjects factor. There was a significant main effect of skills probe, $F(2,34)=37.33, p=.00$. Contrasts revealed that accuracy scores for DRA implementation during Skills Probe $2(M=57.1, S D=24.4)$ and Skills Probe $3(M=76.9, S D=16.8)$ were significantly higher than scores on Skills Probe $1(M=33.1$, $S D=24.4), p=.00$. There was not a significant main effect for group. Scores for DRA accuracy were not significantly different for the Group A or Group B $F(1,17)=1.45, p=.244$.

There was a significant interaction effect between group and skills probe, $F(2,34)=$ $9.99, p=.00$, indicating that accuracy scores for DRA implementation for each skills probe differed for participants in the two groups (see Figure 6). To break down the interaction, contrasts were performed and revealed that accuracy scores for DRA implementation were not significantly different for participants in the control or experimental group at Skills Probe 1 or Skills Probe 3, but were significantly different at Skills Probe 2, $F(1,17)=10.61, p=.005$. Figure 6 depicts the interaction between group and skills probe. At Skills Probe 2, participants in Group A had completed the DRA-implementation training and the participants in Group B had not. The DRA accuracy scores for participants in Group A were significantly higher than the scores for participants in Group B at Skills Probe 2.

\section{TRP-15}

The results of the TRP-15 are depicted in Table 2. Seventeen participants completed the TRP-15. Overall, participants scored the training favorably with average participant rating the 
training questions a 4 (agree slightly). The most frequent score for each question was a 5 (agree). Participants reported that they found the training to be beneficial.

\section{Discussion}

A training package consisting of modeling, rehearsal, and self-monitoring was used to train 20 special educators to write function-based BIPs and conduct DRA for escape-maintained problem behavior. The teachers who participated in the training consisted of all special education teachers for children with emotional and behavioral disorders in the school district. Following training, participants' performance during DRA and quality of their written BIPs improved. The training demonstrated an efficient use of school district resources because a substantial number of school professionals were trained in a single, $7 \mathrm{hr}$ in-service day by only two trainers.

Training teachers and school professionals to write and implement function-based BIPs was important for three reasons. First, schools must be in compliance with federal legislation mandating function-based BIPs (Individuals with Disabilities Education Act, 2004). Second, function-based BIPs are more likely to be effective (e.g., Filter \& Horner, 2009). Third, because function-based BIPs are more effective, they may be less resource-intensive because teachers will need to spend less time managing challenging behavior. The teachers who completed the training demonstrated accurate development and implementation of a function-based intervention (DRA) that has been empirically supported to be effective for decreasing problem behavior.

The present study extended research on behavioral skills training by incorporating selfmonitoring. Inclusion of self-monitoring permitted the training to be extended beyond a 1:1 trainer-to-trainee ratio to a larger group. In traditional behavioral skills training, the trainer models the skills, role plays, and provides feedback to participants. Inclusion of self-monitoring 
permitted participants to role-play and provided feedback to each other, freeing up trainers to train more participants simultaneously. Training larger groups of participants may result in a more efficient use of training resources and broader dissemination of evidence-based practices.

\section{Implications of Experimental Design}

In the behavior analytic training literature, multiple baseline designs are often used to demonstrate experimental control over training procedures (e.g., DiGennaro, Marten, \& Kleinmann, 2007). Within a multiple baseline design, different participants are exposed to a varied number of baseline sessions before training is conducted. The addition of numerous baseline sessions increases the time necessary for participants to complete the training or mandates that more trainers be present to conduct baseline sessions.

The present study used a modified version of the pretest-posttest control group design (Campbell \& Stanley, 1963), which resulted in all participants eventually receiving training. The modified pretest-posttest control group design may be more efficient than multiple baseline designs for evaluating the efficacy of training approaches. Experimental control may be simultaneously demonstrated for a larger number of participants compared to single-subject designs.

The design of the present study may be a socially valid means of demonstrating experimental control. Social validity refers to the extent to which stakeholders find a procedure to be appropriate and result in meaningful, socially significant outcomes (Wolf, 1978). The pretest-posttest control group design may be more socially valid than a multiple baseline design because it does not necessitate extended periods for baseline data collection. In addition to limiting the number of baseline sessions, the modified pretest-posttest control group design resulted in all participants receiving training. Because these data were collected as part of a real- 
world, clinically relevant training, it was important that all participants were trained. By modifying the pretest-posttest control group design, it was possible to expose all participants to two trainings and demonstrate the effectiveness of the training procedures. This modification resulted in an efficient, effective, and clinically relevant training that could inform the design of future trainings.

\section{Repeated Measures and Social Validity}

The social validity of the training procedures may not have been ideal. Some participants vocally reported finding the repeated skills probes aversive during the training. Additional issues with the social validity of the repeated measures used in the present training may be illustrated by the differential attrition in the BIP-writing training compared to the DRA training. Two participants did not complete the BIP-writing training and one participant only completed Skills Probe 1 for BIP writing.

Although participant behavior during the training suggested participants were not completely satisfied with the procedures, this finding was not reflected on the TRP-15. Overall, participants reported that they found the training to be beneficial on the TRP-15. The discrepancy between what participants reported during the training and what they reported on the TRP-15 may have occurred because participants did not find the training beneficial during the course of the training, but at the completion of the entire training, they found the training to be useful.

The TRP-15 is an indirect way to measure social validity. Participants adopting the skills covered during training into their day-to-day activities may be considered a more direct measure of the social validity of the training procedures. Collecting post-training data on participant adoption of the trained skills may be a direct measure of the social validity of the training. It may 
be beneficial to directly compare the outcomes of the TRP-15 with more direct measures to evaluate if what people report they like about specific training procedures matches what they choose to participate in when provided the opportunity.

\section{General Limitations}

One limitation of the present study was that it was not possible to link participants' demographic data to their training data because participants completed the study as part of a mandatory in-service training. For this reason, it is unclear if the two training groups were similar in terms of experience. Participants were not required to provide explicit consent to participate in the training in accordance with protocol approved by the university-level internal review board as long as the data were completely unidentifiable. Participants were informed at the start of the training that it would not be possible to link them to their data.

Second, we did not collect follow-up data on the quality of participants BIPs or if participants use DRA in their classroom. For this reason, it is unclear how effectively the skills acquired during the training generalized to actual BIPs and implementing behavior interventions in classrooms. Future research should evaluate generality and maintenance of skills acquired during trainings similar to the present study.

Third, it is unclear which components of the present training (didactic instruction, modeling, or self-monitoring) were responsible for increased accurate performance. In real-world trainings, such as the present study, training time is often limited. It may be important to identify which components of the training package contributed to its efficacy to streamline the training. Briefer, more efficient trainings may be a better use of resources as long as the targeted skills are acquired by training participants. 
Fourth, the same sample FBA was included in all skills probes for BIP writing and the same script was used during all skills probes for DRA. It is possible that some of the improvement observed for participants may have been a function of repeated practice with the same materials. It is unclear the extent to which repeatedly practicing improved participant performance, but it is unlikely to account for much of the improvements observed. In the present study, performance for participants in the control groups did not improve substantially from Skills Probe 1 to Skills Probe 2. If the increased in the quality of written BIPs was due to repeated practice with materials, improvements in BIP quality should have been observed for participants in the control group at Skills Probe 2 before they had received any training in BIP writing. Increased BIP quality was not observed for participants in the control group until after that had received the BIP writing training, suggesting that improvements in the quality of their written BIPs was unlikely due to repeatedly practicing with the same materials.

\section{Future Directions}

There are several avenues of future research that may address the limitations or clarify the limits and appropriateness of this and similar training packages. It is unclear if participants adopted the strategies that were covered during the training. Although it is important that participants acquire skills during training, it is also important to evaluate if participants adopt those skills into their everyday practice. Conducting trainings for skills that participants do not find to be useful is an inefficient use of staff, trainer, and agency time and resources. In addition, the present training covered empirically supported best practices that are mandated by law. If participants do not adopt the skills covered in the training, then they may not be using the most effective practices in their classroom or be out of compliance with the law. For these reasons, 
research should evaluate if trainings similar to this one result in adoption of the trained skills into everyday practice.

It may also be important to evaluate what components of the training package participants preferred in addition to identifying the components that were effective at producing improvements in performance. For example, participants may have a preference for the selfmonitoring and feedback components of the DRA-implementation training. Knowing which training components participants prefer can inform future, socially valid trainings. If participants preferred components that were not effective, it would be beneficial to identify why participants preferred those components. It may then be possible to evaluate how to modify effective training components to reflect characteristics of the preferred components. For example, if videomodeling was identified as being a preferred, but ineffective component, research could identify what characteristics of video modeling were preferable (e.g., use of technology). Effective, but less preferred, training components could be modified to include technology (e.g., video-based performance feedback).

The present study evaluated if self-monitoring could be incorporated into a training package as a replacement for 1:1 trainer-trainee role playing and performance feedback. The training package was effective, but it is still unclear to what extent self-monitoring contributed to its efficacy. Future research could evaluate self-monitoring in isolation or combination with other training components, such as didactic instruction, to evaluate the extent to which selfmonitoring contributes to new skill acquisition.

The present study used role-plays and hypothetical data to measure how well participants could write BIPs and implement DRA prior to training. Baseline performance in the present study could have been affected by the contrived nature of the skills probes. Participants may 
have performed differently if data were collected in real-life situations. Collecting samples of written BIP's and data on the interventions the participants used with students in their classroom prior to and following the training may be a more naturalistic way to collect data on participants' performance. Research should compare the baseline performance across both measures (i.e., a priori naturalistic data collection versus contrived samples of performance on the training day) to determine if contrived baseline samples match participant behavior in their classrooms.

The BSP-QE was incorporated as an objective measure of the quality of participants' written BIPs in the present study. The BSP-QE assigns BIPs to different qualitative categories (weak, underdeveloped, good, or superior) based on the global score. Presumably, each of these categories is indicative of the likely success of the plan in reducing problem behavior. However, it is unclear the extent to which these qualitative labels are actually associated with the relative successfulness of a BIP. Research should compare how BSP-QE scores and the relative successfulness of a BIP at reducing challenging behavior are related.

The present study aimed to train school professionals to implement and write functionbased BIPs. Teachers are important stakeholders when considering the social validity of a behavior intervention, but the students for whom the intervention is developed are also key stakeholders. For this reason, it may be important to evaluate if students prefer function-based BIPs over non-function-based BIPs. Children's preference for behavior interventions is not always intuitive. For example, some children prefer function-based interventions with a punishment component over a function-based intervention without punishment (Hanley, Piazza, Fisher, \& Maglieri, 2005). It is also possible that children may prefer reinforcement-based BIPs that consist of arbitrary reinforcers (e.g., computer time, extra recess, candy) over function-based interventions. Although we know that function-based interventions are more likely to be 
effective, it is also important to consider what interventions the children would like to be in effect. If effective, non-function-based interventions are preferred by children, and schools are able to support and implement such interventions, the best course of action may be to implement the non-function-based intervention or to combine function-based and non-function-based interventions. 


\section{References}

Browning-Wright, D., Mayer, G. R., Cook, C. R., Crews, S. D., Kraemer, B. R., \& Gale, B. (2007). A preliminary study on the effects of training using the behavior support plan quality evaluation guide (BSP-QE) to improve positive behavioral support plans. Education and Treatment of Children, 20, 89-106.

Browning-Wright, D., Saren, D., \& Mayer, G. R. (2003). The behavior support plan quality evaluation guide. Retrieved on March 2012 from http://www.pent.ca.gov.

Campbell, D. T. \& Stanley, J. C. (1963). Experimental and quasi-experimental designs for research. Chicago: Rand McNally.

Carr, E. G. \& Durand, V. M. (1985). Reducing behavior problems through functional communication training. Journal of Applied Behavior Analysis, 18, 111-126.

Codding, R. S., Feinberg, A. B., Dunn, E. K., \& Pace, G. P. (2005). Effects of immediate performance feedback on implementation of behavior support plans. Journal of Applied Behavior Analysis, 38, 205-219.

Cook, C. R., Crews, D. S., Browning-Wright, D., Mayer, G. R., Gale, B., Kraemer, B., \& Gresham, F. M. (2007). Establishing and evaluating the substantive adequacy of positive behavioral support plans. Journal of Behavioral Education, 16, 191-206.

DiGennaro, F. D., Martens, B. K., \& Kleinmann, A. E. (2007). A comparison of performance feedback procedures on teachers' treatment implementation integrity and students' inappropriate behavior in special education classrooms. Journal of Applied Behavior Analysis, 40, 447-461. 
DiGennaro-Reed, F. D., Codding, R., Catania, C. N., \& Maguire, H. (2010). Effects of video modeling on treatment integrity of behavioral interventions. Journal of Applied Behavior Analysis, 43, 291-295.

Filter, K. J. \& Horner, R. H. (2009). Function-based academic interventions for problem behavior. Education and Treatment of Children, 32, 1-19.

Hammond, J. L., Iwata, B. A., Fritz, J. N., \& Dempsey, C. M. (2011). Evaluation of fixed momentary DRO schedules under signaled and unsignaled arrangements. Journal of Applied Behavior Analysis, 44, 69-81.

Hanley, G. P., Iwata, B. A., \& McCord, B. E. (2003). Functional analysis of problem behavior: A review. Journal of Applied Behavior Analysis, 36, 147-185.

Hanley, G. P., Iwata, B. A., \& Thompson, R. H. (2001). Reinforcement schedule thinning following treatment with functional communication training. Journal of Applied Behavior Analysis, 34, 17-38.

Hanley, G. P., Piazza, C. C., Fisher, W. W., \& Maglieri, K.A. (2005). On the effectiveness of and preference for punishment and extinction components of function-based interventions. Journal of Applied Behavior Analysis, 38, 51-65.

Individuals with Disabilities Education Act of 2004, 20 U.S.C. §1401-82 (2004).

Ingram, K., Lewis-Palmer, T., \& Sugai, G. (2005). Function-based intervention planning: Comparing the effectiveness of FBA function-based and non-function-based intervention plans. Journal of Positive Behavior Interventions, 7, 224-236.

Kraemer, B. R., Cook, C. R., Browning-Wright, D., Mayer, G. R., \& Wallace, M. D. (2008). Effects of training on the use of the behavior support plan quality evaluation guide with 
autism educators: A preliminary investigation examining positive behavior support plans. Journal of Positive Behavior Interventions, 10, 179-189.

Lalli, J. S., Browder, D. M., Mace, F. C., \& Brown, D. K. (1993). Teacher use of descriptive analysis data to implement interventions to decrease students' problem behavior. Journal of Applied Behavior Analysis, 26, 227-238.

Lalli, J. S., Casey, S., \& Kates, K. (1995). Reducing escape behavior and increasing task completion with functional communication training, extinction, and response chaining. Journal of Applied Behavior Analysis, 28, 261-268.

Moore, J. W., Edwards, R. P., Sterling-Turner, H. E., Riley, J., DuBard, M., \& McGeorge, A. (2002). Teacher acquisition of functional analysis methodology. Journal of Applied Behavior Analysis, 35, 73-77.

Moore, J. W., \& Fisher, W. W. (2007). The effects of videotape modeling on staff acquisition of functional analysis methodology. Journal of Applied Behavior Analysis, 40, 197-202.

Newcomer, L. L. \& Lewis, T. J. (2004). Functional behavior assessment: An investigation of assessment reliability and effectiveness of function-based interventions. Journal of Emotional and Behavior Disorders, 12, 168-181.

Noell, G. H., Duhon, G. J., Gatti, S. L., \& Connell, J. E. (2002). Consultation, follow-up, and implementation of behavior management interventions in general education. School Psychology Review, 31, 217-234.

Plavnick, J. B., Ferreri, S. J., \& Maupin, A. N. (2010). The effects of self-monitoring on the procedural integrity of a behavioral intervention for young children with developmental disabilities. Journal of Applied Behavior Analysis, 43, 315-320. 
Scott, T. M., Anderson, C. M., \& Spaulding, S. A. (2008). Strategies for developing and carrying out functional assessment and behavior intervention planning. Preventing School Failure, $52,39-49$.

Scott, T. M., Liaupsin, C., Nelson, C. M., McIntyre, J. (2005). Team-based functional behavior assessment as a proactive public school process: A descriptive analysis of current barriers. Journal of Behavioral Education, 14, 57-71.

St. Peter Pipkin, C., Vollmer, T. R., \& Sloman, K. N. (2010). Effects of treatment integrity failures during differential reinforcement of alternative behavior: A translational model. Journal of Applied Behavior Analysis, 43, 47-70.

Sugai, G., Lewis-Palmer, T., \& Hagan-Burke, S. (1999-2000). Overview of the functional behavioral assessment process. Exceptionality, 8, 149-160.

Sugai, G., Sprague, J. R., Horner, R. H., \& Walker, H. M. (2000). Preventing school violence: The use of office discipline referrals to assess and monitor school-wide discipline interventions. Journal of Emotional and Behavioral Disorders, 8, 94-101.

Tiger, J. H., Hanley. G. P., \& Bruzek, J. (2008). Functional communication training: A review and practical guide. Behavior Analysis in Practice, 1, 16-23.

Van Acker, R., Boreson, L., Gable, R. A., \& Potterton, T. (2005). Are we on the right course? Lessons learned about current FBA/BIP practices in schools. Journal of Behavioral Education, 14, 35-56.

Vollmer, T. R., Sloman, K. N., \& St Peter Pipkin, C. (2008). Practical implications of data reliability and treatment integrity monitoring. Behavior Analysis in Practice, 1, 4-11. 
Wehby, J. H., Lane, K. L., \& Falk, K. B. (2003). Academic instruction for students with emotional and behavioral disorders. Journal of Emotional and Behavioral Disorders, 11, 194-197.

Witt, J. C., Martens, B. K., \& Elliott, S. N. (1984). Factors affecting teachers' judgments of the acceptability of behavioral interventions: Time involvement, behavior problem severity, and type of intervention. Behavior Therapy, 15, 204-209.

Winborn, L., Wacker, D. P., Richman, D. M., Asmus, J., \& Geier, D. (2002). Assessment of mand selection for functional communication training packages. Journal of Applied Behavior Analysis, 35, 295-298.

Wolf, M. M. (1978). Social validity: The case for subjective measurement or how applied behavior analysis is finding its heart. Journal of Applied Behavior Analysis, 11, 203-214. 
Table 1

Descriptions and reasons for including the six concepts of PBS planning in the BSP-QE

\begin{tabular}{|c|c|c|}
\hline Key concept & Description & Reason \\
\hline Behavior function & $\begin{array}{l}\text { Behavior serves a particular } \\
\text { function for the student (e.g., } \\
\text { positive or negative } \\
\text { reinforcement). }\end{array}$ & $\begin{array}{l}\text { The BIP must identify the } \\
\text { function of the problem } \\
\text { behavior in order to develop a } \\
\text { plan that teaches a } \\
\text { functionally equivalent } \\
\text { replacement behavior. }\end{array}$ \\
\hline Situational specificity & $\begin{array}{l}\text { Behavior is related to the } \\
\text { context/environment in which } \\
\text { it occurs. }\end{array}$ & $\begin{array}{l}\text { Something is either in the } \\
\text { environment or not in the } \\
\text { environment, which increases } \\
\text { the likelihood the behavior } \\
\text { will occur. }\end{array}$ \\
\hline Behavior change & $\begin{array}{l}\text { Changing behavior involves } \\
\text { both the environmental } \\
\text { features and teaching a } \\
\text { functionally equivalent } \\
\text { behavior that student can use } \\
\text { to satisfy the function of the } \\
\text { behavior in an acceptable way. }\end{array}$ & $\begin{array}{l}\text { The complete BIP must } \\
\text { address both strands: make } \\
\text { environmental changes that } \\
\text { support, and specify how to } \\
\text { teach or prompt functionally } \\
\text { equivalent acceptable } \\
\text { behavior. }\end{array}$ \\
\hline Reinforcement tactics & $\begin{array}{l}\text { New behavior must be } \\
\text { reinforced to result in } \\
\text { behavioral increases, } \\
\text { generalized performance, and } \\
\text { maintenance. }\end{array}$ & $\begin{array}{l}\text { BIP plan must specify } \\
\text { reinforcement for new, } \\
\text { functionally equivalent } \\
\text { behavior. }\end{array}$ \\
\hline Reactive Strategies & $\begin{array}{l}\text { Implementers need to know } \\
\text { how to handle problem } \\
\text { behavior if it occurs again. }\end{array}$ & $\begin{array}{l}\text { BIP plan must specify reactive } \\
\text { strategies. }\end{array}$ \\
\hline $\begin{array}{l}\text { Team coordination and } \\
\text { communication }\end{array}$ & $\begin{array}{l}\text { For optimal team } \\
\text { performance, it is important to } \\
\text { indicate who is responsible for } \\
\text { carrying out each element of } \\
\text { the plan. And, communication } \\
\text { needs to be between all } \\
\text { important stakeholders, } \\
\text { frequently enough to result in } \\
\text { the progress monitoring } \\
\text { necessary to achieve success. }\end{array}$ & $\begin{array}{l}\text { BIP plan must specify who is } \\
\text { responsible for implementing } \\
\text { each of the plan components } \\
\text { in order to build a system of } \\
\text { accountability and evaluate } \\
\text { the fidelity of the plan. Plan } \\
\text { must specify who } \\
\text { communicates with whom, } \\
\text { how frequently, and in what } \\
\text { manner. }\end{array}$ \\
\hline
\end{tabular}


Table 2

Participant demographic data

\begin{tabular}{|c|c|c|c|c|c|}
\hline \multirow[b]{2}{*}{ Age } & \multirow[b]{2}{*}{ Sex } & \multirow[b]{2}{*}{ Highest Degree } & \multicolumn{2}{|c|}{ Years } & \multirow[b]{2}{*}{ Number of Student with BIPs } \\
\hline & & & In Position & Of Teaching & \\
\hline 33 & $\mathrm{M}$ & Masters & 6 & 8 & 11 \\
\hline 44 & M & Bachelors & 7 & 16 & 8 \\
\hline 49 & $\mathrm{~F}$ & Masters & 6 & 6 & 3 \\
\hline 38 & $\mathrm{~F}$ & Masters & 1 & 14 & 30 \\
\hline 44 & M & Bachelors & 12 & 20 & 14 \\
\hline 37 & M & Masters & 2 & 4 & 7 \\
\hline 24 & $\mathrm{~F}$ & Bachelors & 2 & 2 & \\
\hline 35 & M & Masters & 4 & 4 & 20 \\
\hline 40 & M & Masters & 5 & 14 & 10 \\
\hline 25 & $\mathrm{~F}$ & Masters & 1 & 1 & 0 \\
\hline 31 & $\mathrm{M}$ & Bachelors & 1 & 4 & 5 \\
\hline 38 & $\mathrm{~F}$ & Masters & 7 & 11 & 5 \\
\hline 52 & $\mathrm{M}$ & Masters & 4 & 20 & 25 \\
\hline 35 & $\mathrm{M}$ & Masters & 2 & 11 & 9 \\
\hline 57 & $\mathrm{~F}$ & Masters & 1 & 22 & 5 \\
\hline 25 & $\mathrm{~F}$ & Masters & 1 & 2 & 8 \\
\hline 31 & $\mathrm{~F}$ & Masters & 2 & 5 & 1 \\
\hline 56 & $\mathrm{~F}$ & Masters & 26 & 33.5 & 2 \\
\hline 24 & $\mathrm{~F}$ & Masters & 1 & 1 & 2 \\
\hline 51 & $\mathrm{~F}$ & Masters & 7 & 15 & 2 \\
\hline 32 & $\mathrm{~F}$ & Masters & 4 & 7 & 6 \\
\hline 54 & $\mathrm{~F}$ & Masters & 13 & 22 & 12 \\
\hline
\end{tabular}


Table 3

Summary of participants' responses on the TRP-15

\begin{tabular}{|c|c|c|}
\hline Question & Mean & Mode \\
\hline $\begin{array}{l}\text { The strategies I learned would be an acceptable way to } \\
\text { deal with a child's problem behavior. }\end{array}$ & 4.8 & 5 \\
\hline $\begin{array}{l}\text { Most teachers would find the strategies described } \\
\text { appropriate for behavior problems. }\end{array}$ & 4.3 & 5 \\
\hline $\begin{array}{l}\text { The strategies described should be effective in changing a } \\
\text { child's problem behavior. }\end{array}$ & 4.8 & 5 \\
\hline I would suggest that other teachers attend this training. & 4.2 & 5 \\
\hline The training was applicable to issues in my classroom. & 4.5 & 6 \\
\hline The trainers were well-prepared for the training session. & 4.9 & 5 \\
\hline $\begin{array}{l}\text { I would be willing to use the strategies that I learned in my } \\
\text { classroom. }\end{array}$ & 4.8 & 5 \\
\hline $\begin{array}{l}\text { The strategies I learned would not result in negative side- } \\
\text { effects for the child. }\end{array}$ & 4.5 & 5 \\
\hline $\begin{array}{l}\text { The strategies I learned would be appropriate for a variety } \\
\text { of children. }\end{array}$ & 4.7 & 6 \\
\hline $\begin{array}{l}\text { The trainers presented material in a clear and } \\
\text { understandable way. }\end{array}$ & 4.5 & 5 \\
\hline $\begin{array}{l}\text { The trainers included an appropriate amount of interaction } \\
\text { in the training. }\end{array}$ & 5.0 & 5 \\
\hline $\begin{array}{l}\text { The strategies I learned are "do-able" in a classroom } \\
\text { environment. }\end{array}$ & 4.4 & 5 \\
\hline $\begin{array}{l}\text { I liked the procedures the procedures I learned about in } \\
\text { this training. }\end{array}$ & 4.5 & 5 \\
\hline $\begin{array}{l}\text { The trainers allowed time for questions, and answered } \\
\text { questions appropriately. }\end{array}$ & 5.3 & 5 \\
\hline
\end{tabular}

Note: Rating Scale: 1=Strongly Disagree 2=Disagree 3=Disagree Slightly 4=Agree Slightly 5=Agree 6=Strongly Agree 


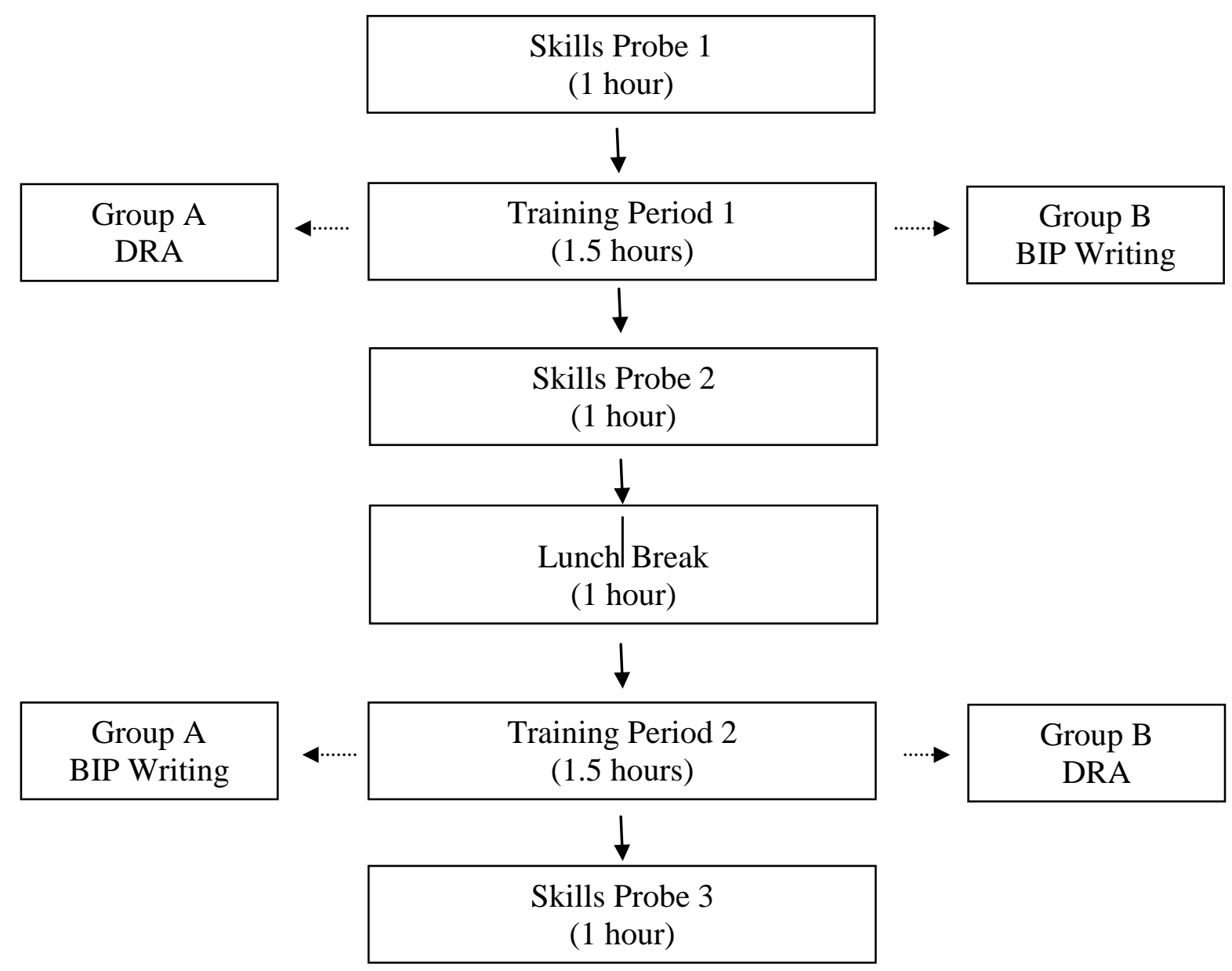

Figure 1. Schematic depicting the training schedule 

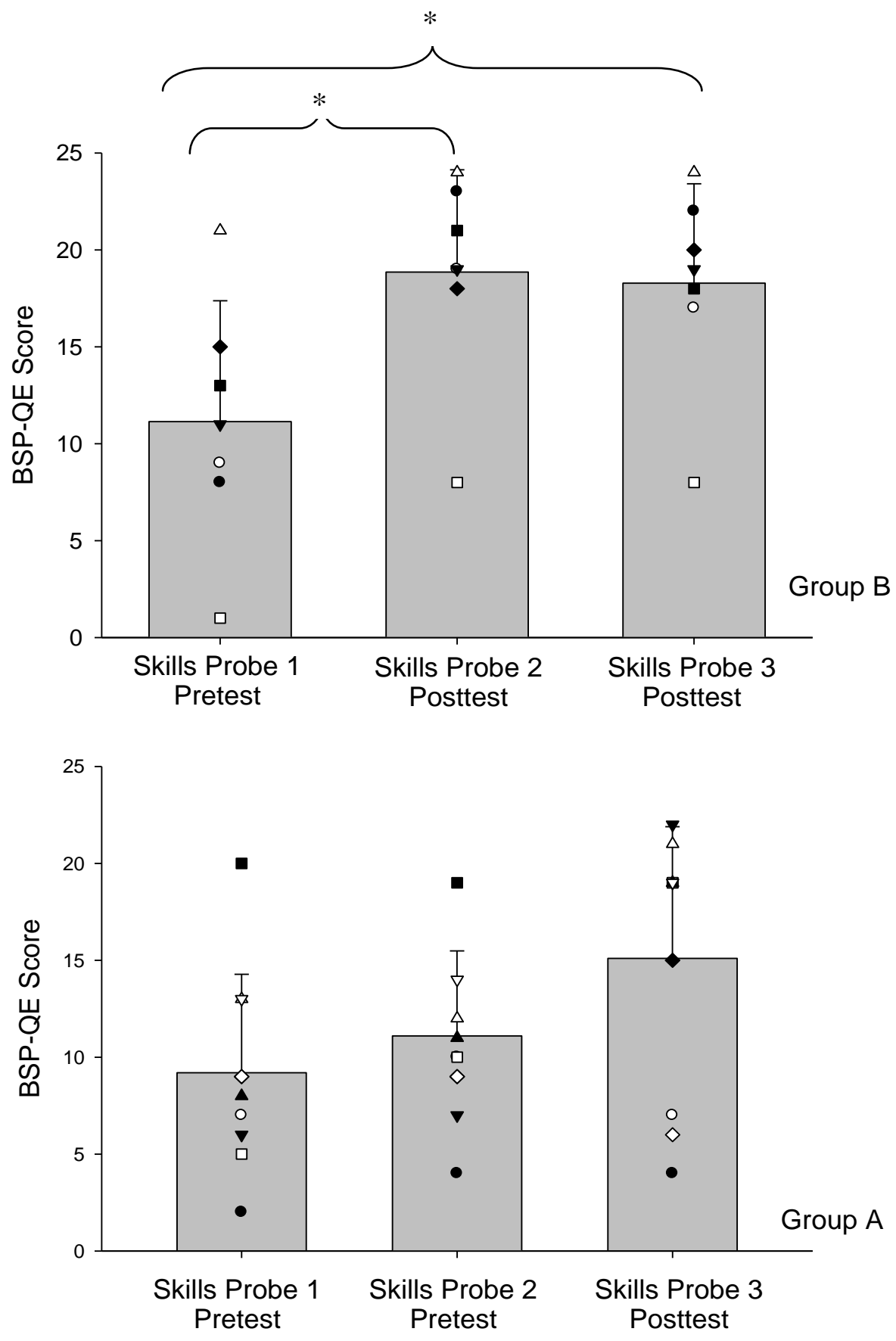

Figure 2. Scores on the BSP-QE as a function of skill probe. The top panel depicts the data for the Group B and the bottom panel depicts the data for the Group A. Each data point depicts the data for a single participant. The bars depict the mean group performance at each skills probe. Stars indicate significance at the $p<.05$ level. Error bars indicate one standard deviation. 


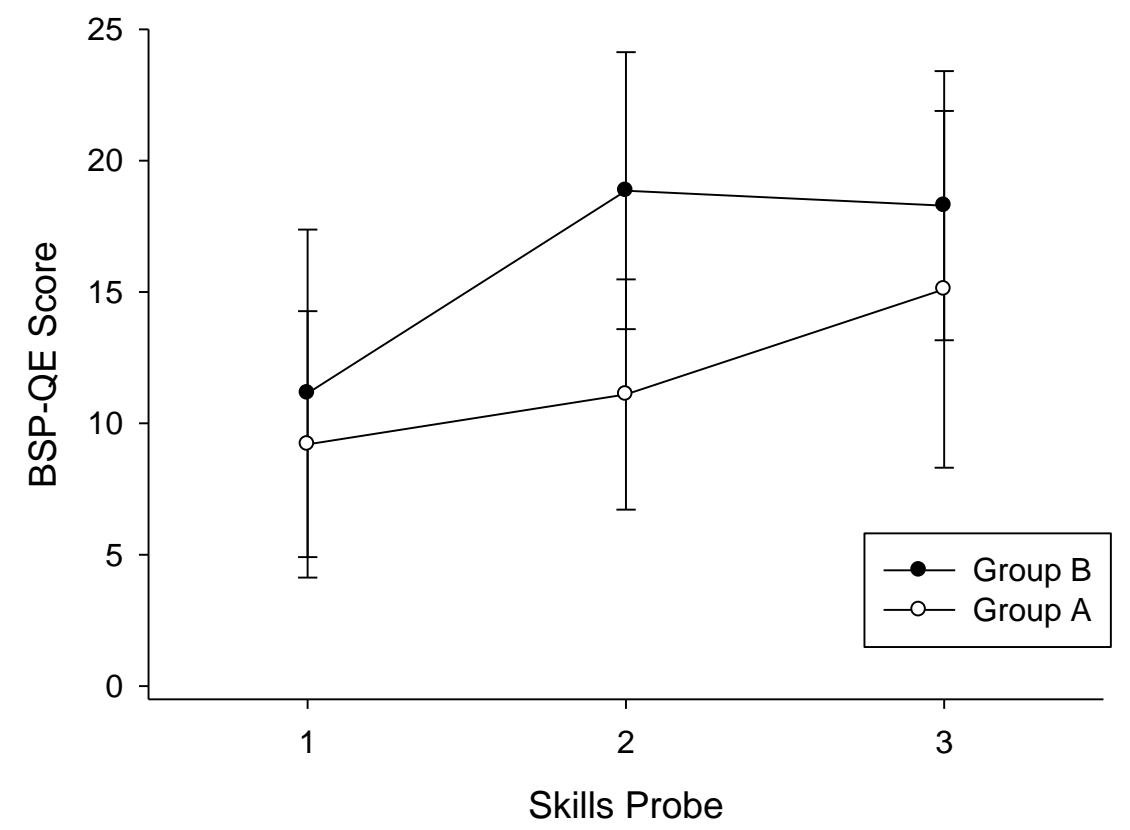

Figure 3. BSP-QE scores during Skills Probe 1, 2 and 3 for the Group B and Group A. Group B is depicted by the closed symbols and Group A is depicted by the open symbols. Error bars indicate one standard deviation. 


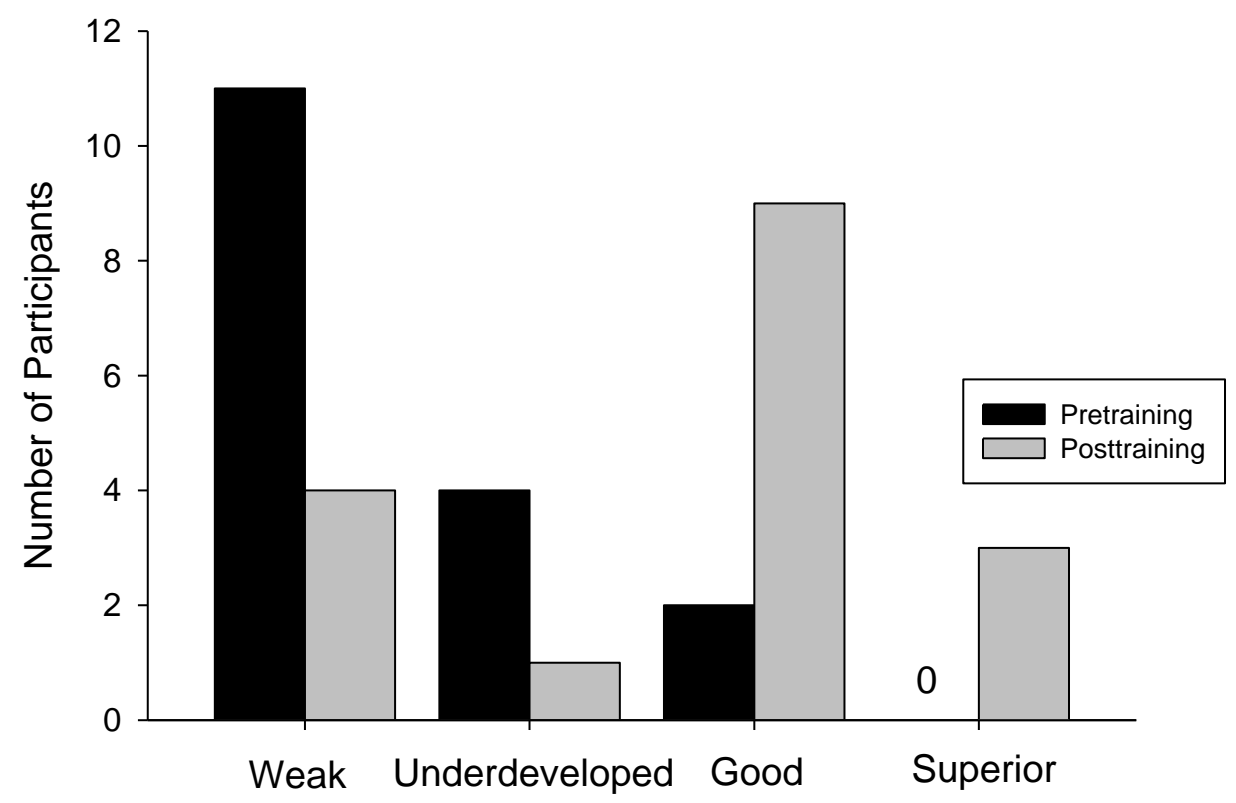

Figure 4. Number of BIPs within each quality category prior to training (black bars) and following training (gray bars). 


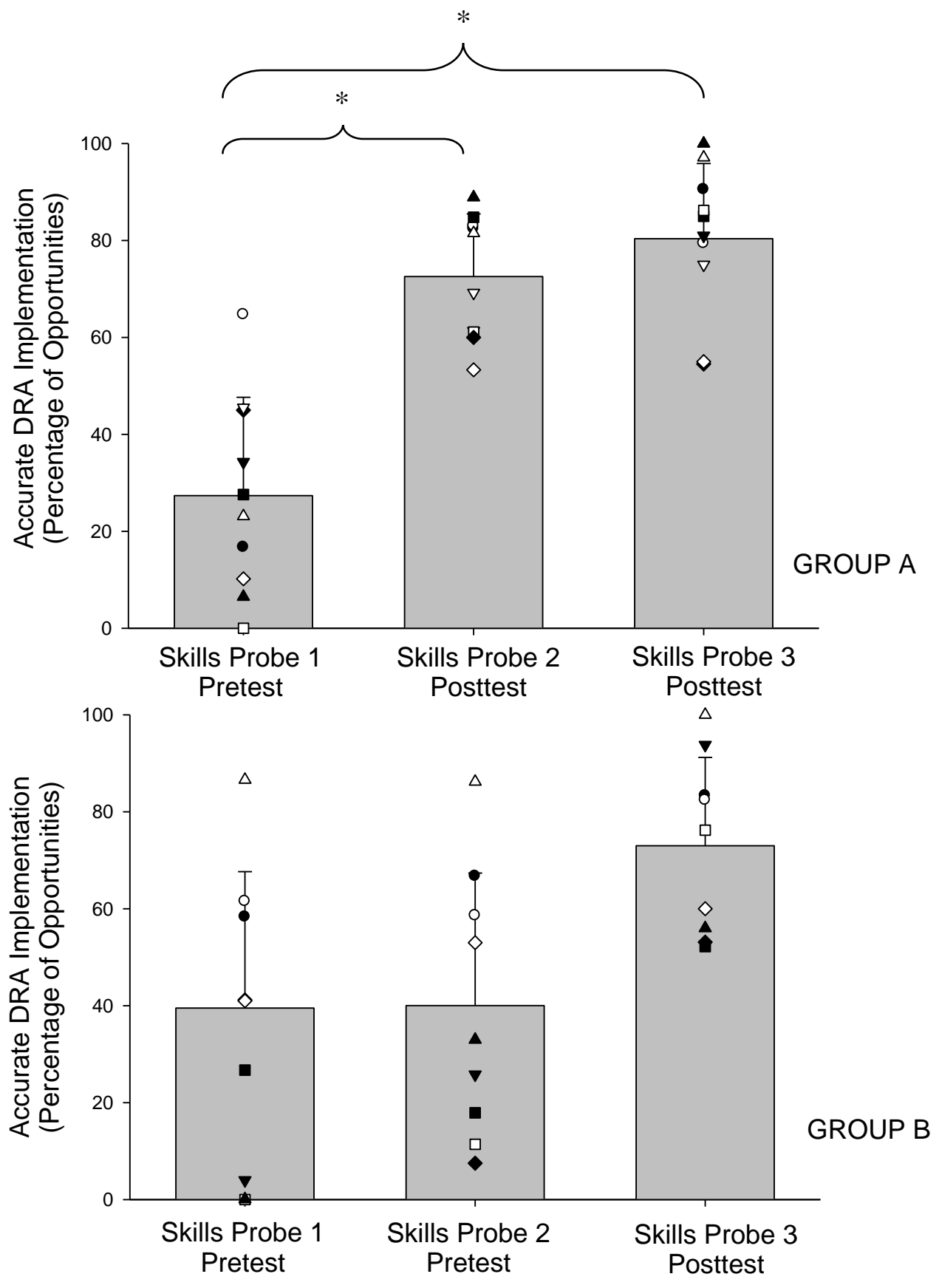

Figure 5. Accuracy scores for DRA implementation as a function of skill probe. The top panel depicts the data for the Group A and the bottom panel depicts the data for the Group B. Each data point depicts the data for a single participant. Stars indicate significance at the $p<.05$ level. The bars depict the mean group performance at each skills probe. Error bars indicate one standard deviation. 


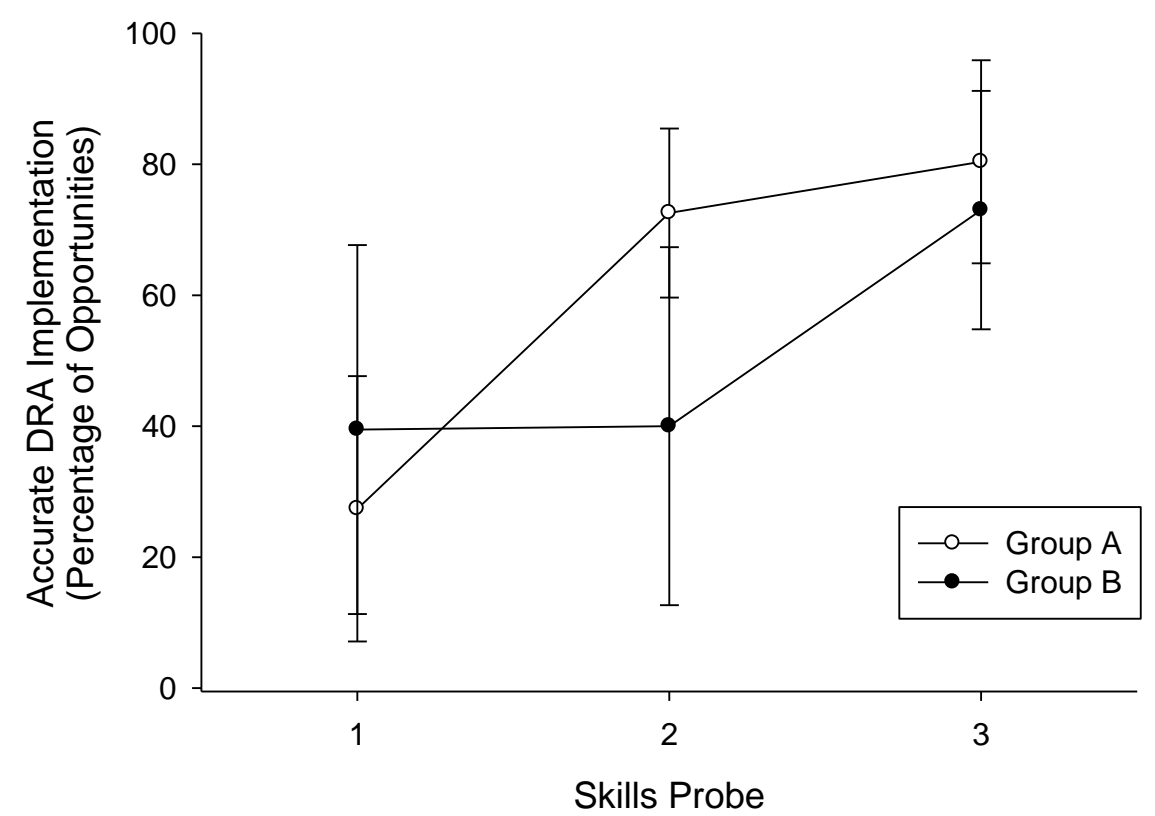

Figure 6. Accuracy scores during Skills Probe 1, 2 and 3 for the Group B and Group A. Group B is depicted by the closed symbols and Group A is depicted by the open symbols. Error bars indicate one standard deviation. 


\section{Appendix A}

\section{Sample FBA}

\section{Monongalia County Schools}

Functional Behavior Assessment (FBA) Worksheet

Adapted from Association of Positive Behavior Support (APBS)

Student/Grade: Max/First Grade

School: Morgantown Elementary School

Team Members: Mrs, Brown, Principle Jones, Mr. Edwards

The first portions of this FBA Worksheet (thro

be completed at the FBA referral meeting.

Student Strengths: Identify at least 3 strengths or contributions the student brings to school

Max is an energetic six-year-old boy who is very helpful to teacher and classmates, makes friends easily, reads at a second-grade level.

Problem Behavior(s): Identify the Target Behaviors to be assessed

Operationally define the Target Behaviors (up to 3)

Disruption: ripping academic materials, breaking pencils, knocking over furniture.

General examples of problem behaviors:

Truant/Tardy, Physical Aggression, Disruptive, Theft, Unresponsive, Inappropriate Language, Noncompliance, Vandalism, Withdrawn, Verbal Harassment, Work Refusal, Verbally Inappropriate, Self-injury

Identifying Location/Intensity: Where, When and With Whom Problem Behaviors are most likely

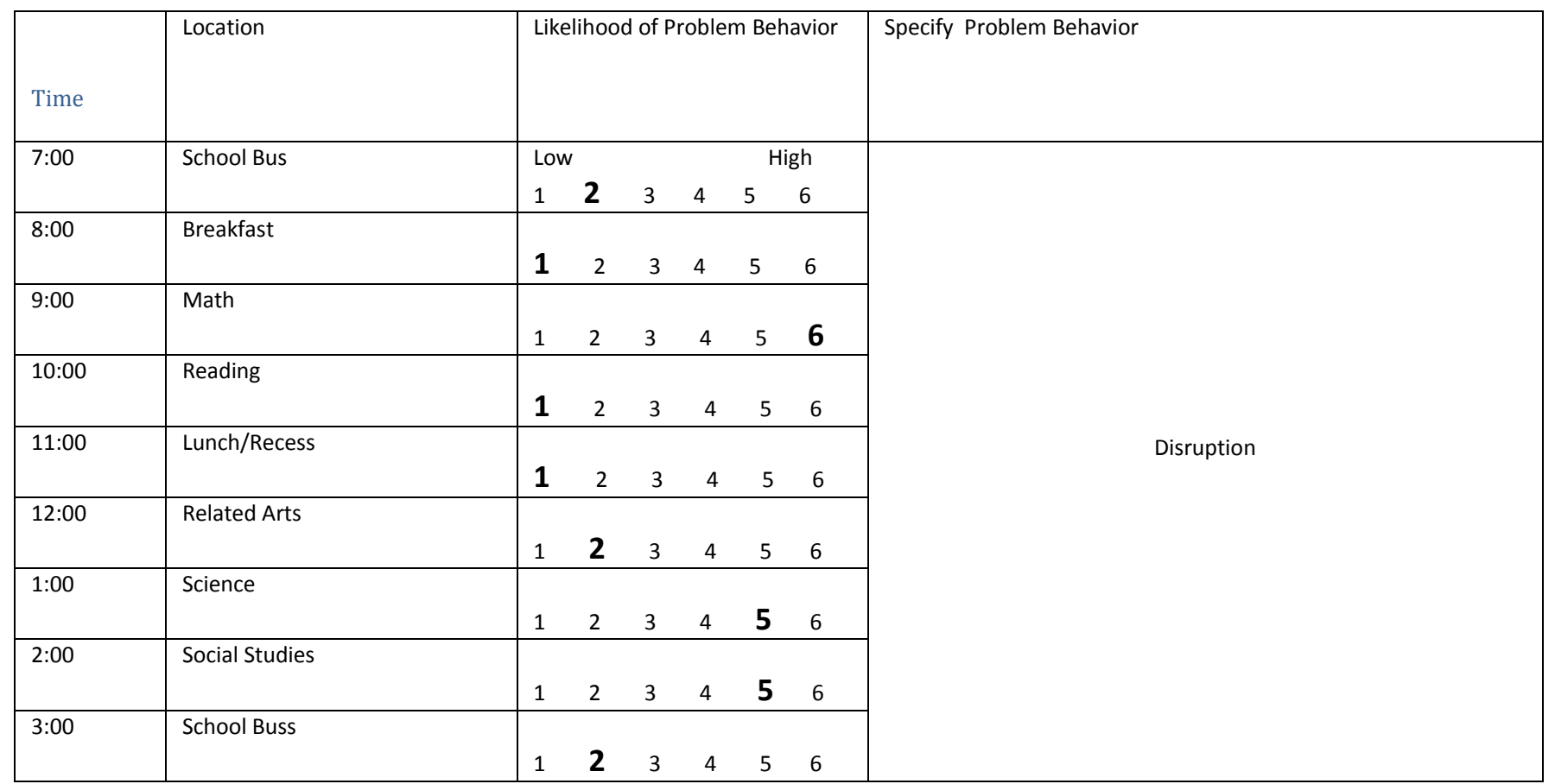

Date: February 22, 2012

Birth Date: July 1, 2006

Classroom Teacher: Mrs. Smith 
Previous Positive Behavior Interventions attempted (attach supporting documentation and explain

below):

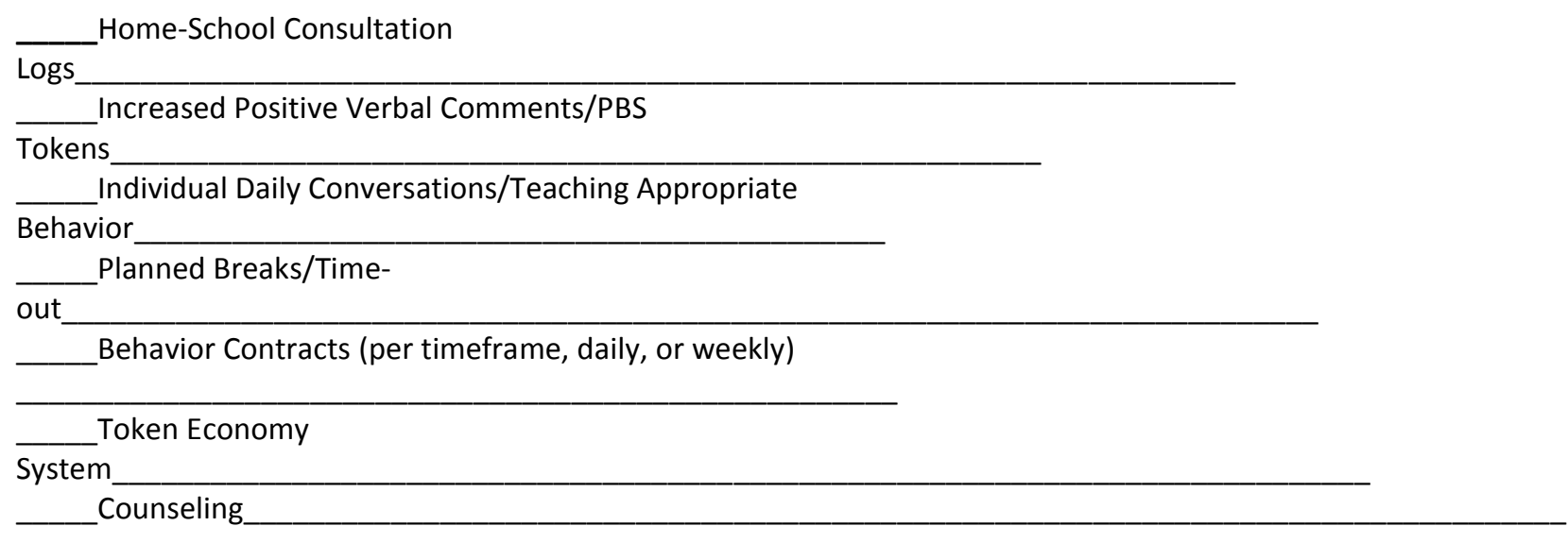

X___other: This is the first FBA completed for Max

Summary of Student Interview and Reinforcement Survey:

Toys and extra recess were identified by Max as potential rewards.

\section{Results of the Forced Choice Reinforcement Survey:} (MAS):

Adult Approval (A)

Competitive Approval (CM)

Peer Approval (P)

Independent Rewards (I)

X__Consumable Rewards (CN)
Results of Motivation Assessment Scale Self-Stimulatory

$\mathbf{X}$ Escape/Avoidance
Attention
Tangible

\section{Summarizing the Observations:}

Max was observed by the FBA team across the school day in a variety of settings. The FBA team observed Max during several academic periods. During math, science and social studies Max was observed to rip up academic worksheets and break pencils. Disruptive behavior occurred more frequently during independent work periods than during large-group or small group instruction. During independent work periods, the classroom aid frequently sat next to Max to encourage him to work. Disruption was not observed during reading, lunch, and related art. 
Antecedent and Consequence Analysis Charts: Multiple Antecedents can trigger the same behavior and multiple Consequences can directly follow the same behavior. This chart outlines the relationships.

\begin{tabular}{|c|c|c|}
\hline \multicolumn{3}{|l|}{ Target Behavior \#1 } \\
\hline Antecedent & Specific Observable Behavior & Consequence \\
\hline $\begin{array}{l}\text { Max's teacher asks Max to complete } \\
\text { worksheet. }\end{array}$ & Max breaks pencil & $\begin{array}{l}\text { Teacher ignores Max and praises other } \\
\text { students for completing their work. }\end{array}$ \\
\hline $\begin{array}{l}\text { Max is prompted to read silently } \\
\text { from his science textbook. }\end{array}$ & $\begin{array}{l}\text { Max rips corners of textbook } \\
\text { pages, throws book in trash }\end{array}$ & $\begin{array}{l}\text { Problem behavior is ignored. Peers } \\
\text { laugh at Max. }\end{array}$ \\
\hline Max is presented a science test & $\begin{array}{l}\text { Max tears his test into two } \\
\text { pieces }\end{array}$ & $\begin{array}{l}\text { Teacher continues to read test } \\
\text { instructions to class. Teaching } \\
\text { assistant tapes test together and tells } \\
\text { Max he will complete it during recess. }\end{array}$ \\
\hline
\end{tabular}

Make Hypothesizing Statements: The antecedents and consequences are analyzed to see which function(s) the behavior fulfills. Problem behavior can also serve more than one function. Multiple pieces of information, combined with direct observation of the behavior are used in determining the function of the behavior.

Make the hypothesizing statement in the following format: IF . . THEN . . . BECAUSE . . F For example, IF Antecedent $X$ occurs, THEN Problem Behavior $Y$ occurs, BECAUSE of the maintaining consequence $Z$ and the Function/Need the Problem Behavior serves.

If Max is presented with independent work during math, science, or social studies, then he is more likely to engage in disruptive behavior because he may postpone or escape completing the assignment.

What consequences appear most likely to maintain the problem behavior(s)? (Function)

Things that are Obtained:

_ Adult attention (positive or negative)

- Peer attention

- Preferred activity

- Money/things

- Other:
Things Avoided or Escaped From:

$\mathbf{X}$ Hard tasks

_ Reprimands

$\mathbf{X}$ Undesirable activity

_ Negative Peer Interactions

- Physical effort

_Adult attention

Other: Independent work

Level of confidence that the FBA Worksheet is accurate with the data collected?

\begin{tabular}{|cccccc|}
\hline $\begin{array}{c}\text { Not very confident } \\
1\end{array}$ & 2 & 3 & 4 & \multicolumn{2}{c|}{ Very Confident } \\
\hline
\end{tabular}




\section{Appendix B}

\section{Structured BIP Form}

\section{CONFIDENTIAL - DO NOT DISPLAY}

\section{BEHAVIOR SUPPORT PLAN}

For Behavior Interfering with Student's Learning or the Learning of His/Her Peers
This BSP attaches to:
IEP date:
504 plan date:
Team meeting date:

\section{Student Name}

Today's Date

\section{Next Review Date}

1. The behavior impeding learning is (describe what it looks like)

2. It impedes learning because

3. The need for a Behavior Support Plan $\square$ early stage intervention $\square$ moderate $\square$ serious $\square$ extreme

4. Frequency or intensity or duration of behavior
$\square$ reported by
and/or $\square$ observed by

\section{PREVENTION PART I: ENVIRONMENTAL FACTORS AND NECESSARY CHANGES}

What are the predictors for the behavior? (Situations in which the behavior is likely to occur: people, time, place, subject, etc.) ธิ. 5.

What supports the student using the problem behavior? (What is missing in the environment/curriculum or what is in the environment curriculum that needs changing?)

6.

Remove student's need to use the problem behavior

What environmental changes, structure and supports are needed to remove the student's need to use this behavior? 7.

Who will establish? Who will monitor? Frequency?

\section{ALTERNATIVES PART II: FUNCTIONAL FACTORS AND NEW BEHAVIORS TO TEACH AND SUPPORT}

\section{$\infty 8$.}

Accept a replacement behavior that meets same need

What team believes the student should do INSTEAD of the problem behavior? (How should the student escape/protest/ avoid or get his/her need met in an acceptable way?) 9.

= What teaching Strategies/Necessary Curriculum/Materials are needed? (List successive teaching steps for student to learn 으 replacement behavior/s) 10.

Who will establish? Who will monitor? Frequency?

\footnotetext{
을 11 .

Selection of reinforcer based on:

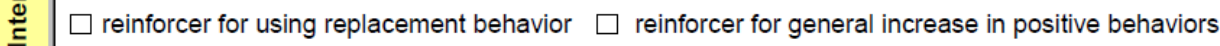
By whom? Frequency?
} 


\section{EFFECTIVE REACTION PART III: REACTIVE STRATEGIES}

What strategies will be employed if the problem behavior occurs again?

12.

1. Prompt student to switch to the replacement behavior

2. Describe how staff should handle the problem behavior if it occurs again

3. Positive discussion with student after behavior ends

Optional:

4. Any necessary further classroom or school consequences

Personnel?

\section{OUTCOME PART IV: BEHAVIORAL GOALS}

Behavioral Goal(s)

13.

Required: Functionally Equivalent Replacement Behavior (FERB) Goal

\begin{tabular}{|c|c|c|c|c|c|c|c|c|}
\hline $\begin{array}{c}\text { By } \\
\text { When }\end{array}$ & Who & $\begin{array}{c}\text { Will do } \mathbf{X} \\
\text { behavior } \\
\text { (line 9) }\end{array}$ & $\begin{array}{c}\text { For the } \\
\text { purpose of } \\
\text { y } \\
\text { (line 8) }\end{array}$ & $\begin{array}{c}\text { Instead of Z } \\
\text { behavior } \\
\text { (line 1) }\end{array}$ & $\begin{array}{c}\text { For the } \\
\text { purpose of } \\
\text { y } \\
\text { (line 8) }\end{array}$ & $\begin{array}{c}\text { Under what } \\
\text { conditional } \\
\text { conditions }\end{array}$ & $\begin{array}{c}\text { At what } \\
\text { level of } \\
\text { proficiency }\end{array}$ & $\begin{array}{c}\text { As } \\
\text { measured } \\
\text { by whom } \\
\text { and how }\end{array}$ \\
\hline & & & & & & & \\
\hline
\end{tabular}

Option 1: Increase General Positive or Decrease Problem Behavior

\begin{tabular}{|l|l|l|l|l|l|}
\hline By when & Who & $\begin{array}{c}\text { Will do what, or } \\
\text { will NOT do what }\end{array}$ & $\begin{array}{c}\text { At what level of } \\
\text { proficiency }\end{array}$ & $\begin{array}{c}\text { Under what } \\
\text { conditions }\end{array}$ & $\begin{array}{c}\text { Measured by } \\
\text { whom and how }\end{array}$ \\
\hline & & & & \\
\hline
\end{tabular}

Option 2: Increase General Positive or Decrease Problem Behavior

\begin{tabular}{|l|l|l|l|l|l|}
\hline By when & Who & $\begin{array}{c}\text { Will do what, or } \\
\text { will NOT do what }\end{array}$ & $\begin{array}{c}\text { At what level of } \\
\text { proficiency }\end{array}$ & $\begin{array}{c}\text { Under what } \\
\text { conditions } \\
\text { whom and how }\end{array}$ \\
\hline & & & & \\
\hline
\end{tabular}

The above behavioral goal(s) are to: $\square$ Increase use of replacement behavior and may also include:

$\square$ Reduce frequency of problem behavior $\square$ Develop new general skills that remove student's need to use the problem behavior

Observation and Analysis Conclusion:

Are curriculum accommodations or modifications also necessary? Where described:

$\square$ yes $\square$ no

Are environmental supports/changes necessary?

$\square$ yes $\square$ no

Is reinforcement of replacement behavior alone enough (no new teaching is necessary)?.

$\square$ yes $\square$ no

Are both teaching of new replacement behavior AND reinforcement needed?

$\square$ yes $\square$ no

This BSP to be coordinated with other agency's service plans?

$\square$ yes $\square$ no

Person responsible for contact between agencies

$\square$ yes $\square$ no 
COMMUNICATION PART V: COMMUNICATION PROVISIONS

Manner and content of communication

14.

\begin{tabular}{|c|c|c|c|c|c|}
\hline 1. Who? & $\begin{array}{c}\text { 2. Under what } \\
\text { condition(s) } \\
\text { (Contingent? } \\
\text { Continuous?) }\end{array}$ & $\begin{array}{c}\text { 3. } \\
\text { Delivery } \\
\text { Manner }\end{array}$ & $\begin{array}{c}\text { 4. Expected } \\
\text { Frequency? }\end{array}$ & 5. Content? & $\begin{array}{c}\text { 6. How will this be } \\
\text { two-way } \\
\text { communication }\end{array}$ \\
\hline & & & & & \\
\hline
\end{tabular}

\begin{tabular}{|c|c|c|c|c|c|}
\hline 1. Who? & $\begin{array}{c}\text { 2. Under what } \\
\text { condition(s) } \\
\text { (Contingent? } \\
\text { Continuous?) }\end{array}$ & $\begin{array}{c}\text { 3. } \\
\text { Delivery } \\
\text { Manner }\end{array}$ & $\begin{array}{c}\text { 4. Expected } \\
\text { Frequency? }\end{array}$ & 5. Content? & $\begin{array}{c}\text { 6. How will this be } \\
\text { two-way } \\
\text { communication }\end{array}$ \\
\hline & & & & & \\
\hline
\end{tabular}

\begin{tabular}{|l|c|c|c|c|c|}
\hline 1. Who? & $\begin{array}{c}\text { 2. Under what } \\
\text { condition(s) } \\
\text { (Contingent? } \\
\text { Continuous?) }\end{array}$ & $\begin{array}{c}\text { 3. } \\
\text { Delivery } \\
\text { Manner }\end{array}$ & $\begin{array}{c}\text { 4. Expected } \\
\text { Frequency? }\end{array}$ & 5. Content? & $\begin{array}{c}\text { 6. How will this be } \\
\text { two-way } \\
\text { communication }\end{array}$ \\
\hline & & & & & \\
\hline
\end{tabular}

\section{PARTICIPATION PART VI: PARTICIPANTS IN PLAN DEVELOPMENT}
$\square$ Student
$\square$ Parent/Guardian
$\square$ Parent/Guardian
$\square$ Educator and Title
$\square$ Educator and Title
$\square$ Educator and Title
$\square$ Administrator
Other
Other 


\section{Appendix C}

\section{Demographic Questionnaire}

Age:

Gender:

$\square$ Male
$\square$ Female
$\square$ Prefer not to disclose

$\square$ Female
$\square$ Prefer not to disclose

Highest degree obtained: $\quad \square$ Bachelor

Master's

Doctoral

Number of years in present position: Total years of experience:

Certifications (e.g., BD, autism, etc.):

Number of students on behavior intervention plans with whom you currently work:

Previous experience writing behavior intervention plans:

Previous experience implementing behavior intervention plans:

Have you ever taken classes in Applied Behavior Analysis? If so, please describe. 


\section{Appendix D}

\section{DRA Pretest/Posttest Script}

\begin{tabular}{|c|c|}
\hline Antecedent & "Child" Behavior \\
\hline \multirow{20}{*}{$\begin{array}{l}\text { Participant will be instructed to use } \\
\text { materials to present an academic task to } \\
\text { the "child" throughout the session. }\end{array}$} & Throw pencil (not at a person) \\
\hline & Comply with instruction \\
\hline & Do not comply \\
\hline & Do not comply \\
\hline & Comply \\
\hline & Kick chair two times \\
\hline & Ask "May I take a break?" \\
\hline & $\begin{array}{l}\text { Do not comply. Yell, "I'm not doing any work for } \\
\text { you EVER!" }\end{array}$ \\
\hline & Hit table \\
\hline & Say "This is really hard, can you help me?" \\
\hline & Kick chair and yell "I want to teak a BREAK!" \\
\hline & Comply \\
\hline & Say, "This is hard. May I have a break please?" \\
\hline & Comply \\
\hline & Comply \\
\hline & Comply \\
\hline & Say "I quit this school!" \\
\hline & Say "Can I have a break from my work please?" \\
\hline & Comply \\
\hline & Punch table \\
\hline
\end{tabular}




\section{Appendix E}

\section{Powerpoint Slides for BIP-Writing Training}

\section{FUNCTION-BASED BEHAVIOR INTERVENTION PLANS}

Aimee Giles, M.S., BCBA

\section{Escape from demands}

Most common function for problem behavior

- Does not preclude conducting FBA

What it looks like in schools:

- Can't identify function of behavior from topography

Evaluate antecedents and consequences

Common antecedents (academic work, delivery of instructions, asked to complete domestic, vocational, or self-care tasks)

Common consequences (avoid work for a short period of time, instruction or demand removed, time-out, sent to office)

Have to look at trend and level of behavior

What do function-based interventions look like?

Deliver the reinforcer you identified during the FBA following a different, appropriate behavior (DRA)

- Deliver the reinforcer you identified during the FBA following period of time when the problem behavior doesn't occur

- Deliver the reinforcer you identified during the FBA at specified times regardless of the occurrence of problem behavior

- Modify the environment to remove the need to use problem behavior
Overview of behavior function

What do we mean when we refer to the function of problem behavior?

- Behavior serves a particular function for the student

(e.g., positive or negative reinforcement)

- Consequences that follow problem behavior $\rightarrow$ reinforce that behavior

Common functions of problem behavior: attention, access to tangibles, escape from demands

- Function-based behavior intervention plans (BIP)

are only as good as the functional behavior

assessment (FBA) of which they are based

What to do for escape-maintained problem behavior?

- Variety of function-based intervention options (including DRA)

-Why use a function-based intervention? - Mandated by IDEA

More effective

- Decreases use of aversive strategies
What do function-based interventions

NOT look like?

- Do not include ONLY arbitrary reinforcers or rewards

- Candy

- Computer

- Toys

- Extra recess

- Does not include ONLY punishment

- Response cost

- Time-out 
How to improve and evaluate functionbased BIP

- Behavior Support Plan Qualitative Evaluation Guide (BSP-QE II)

- Rubric to evaluate the quality of BIP

- May also be used when developing BIPs!

- Copy of BSP-QE II is in Section 4 of your binders

-Also take out Behavior Support Plan form to follow along (Section 5)

\section{Problem behavior (p. 7)}

- Usually limit BIP to one or two functionally equivalent problem behaviors

- Problem behavior needs to be observable and measurable $\rightarrow$ someone not familiar with the student should easily be able to identify behavior when it is happening and when it isn't (line 1)

- You can ask someone not familiar with student to read definition and act it out as a test

- Examples:

- Aggression: hitting, kicking, biting, head butting

- Non-compliance: student does not initiate or follow teacher instruction within 10 seconds

- Should be identified during FBA process

\section{Predictors of behavior (p. 8)}

When, where, and under what conditions can you expect behavior to occur (line 5)

- Should be identified during the FBA process (scatter plot, Antecedent-Behavior-Consequence evaluations, hypothesis statement from FBA)

- May include details about:

- Physical/social setting

Instructional strategies, curriculum, and activities (most common for escape)

Scheduling factors (time of day, transitions)

Degrees of independence (How much prompting)

Degree of participation/choice

\section{Supports for problem behavior (p. 9)}

- Identifies WHY the antecedent variables identified in line 5 support the problem behavior (line 6)

-What is presently in the environment or missing from the environment that results is problem behavior?

- Must be logically related to environmental features targeted in line 5

- Line 5:Instructional strategies, curriculum, and activities (most common for escape) $\rightarrow$ Line 6: academic material is not appropriate for student's academic level; seems like work may take too long to complete

- Line 5: Degrees of independence (How much prompting) $\rightarrow$ Line 6 : current prompt structure is not appropriate for student and 6: current prompt structure is not appropriate
does not help student to answer correctly

- Line 5: Degree of participation/choice $\rightarrow$ student does not have an appropriate way to choose of academic activity

\section{Environmental Structure (p. 10)}

How will the environment be changed to remove the need for the student to use problem behavior (line 7)

- Related to the supports for problem behavior in line 6

- Line 6: academic material is not appropriate for student's academic level; seems like work may take too long to complete $\rightarrow$ Line 7: modify academic content to appropriate level, break work into smaller units

Line 6: current prompt structure is not appropriate for student and does not help student to answer correctly $\rightarrow$ Line 7 : Read out loud written instructions or use visual cues

Line 6: student does not have an appropriate way to choose of academic activity $\rightarrow$ Provide choice between two or more activities at start of class, allow student to choose order of activities

\section{Function of behavior (p.11)}

- The function of problem behavior should be identified in the FBA

- The function should be logically related to the predictors in line 5

- The function should specify what the student gains, avoids, or escapes

- With ESCAPE-maintained problem behavior the function should specify what the student avoids, postpones, or escapes from

- Should NOT include the following terms: revenge, vengeance, control, or power (not observable and there is no appropriate alternative) 


\section{Replacement behavior (p. 12)}

- Should serve the same function as problem behavior - For escape-maintained problem behavior common functionally equivalent replacement behaviors (FERB) include:

- Compliance (if it is reinforced with escape); Needs to be operationally defined and at student's level; Definition: Student initiates or complies with teacher directive within 10 sec of the initial instruction

Request for a break; Can be vocal, picture exchange, signed; may need to be trained

- Choosing activities or order of activities; also may need to be trained

\section{Teaching Strategies (p. 13)}

Must outline teaching strategies for all replacement behaviors

- Should not describe any reactive strategies for problem behavior

- Should not include cathartic response for aggression

- Examples:

- Compliance: Initially student will receive a 2 min break following each instance of compliance with teacher's instructions; prompts is complying with $90 \%$ of all instructions a token. Once the student is complying until student is earning 10 tokens before a break.

. Requesting break: The teacher will model how the student can that breaks are available.

\section{Reinforcers (p.15)}

Identified via the FBA; For escape-maintained problem behavior reinforcer should be a BREAK

Reinforcer vs. Reward

- Should be

Specifically stated $\rightarrow$ break

Contingent $\rightarrow$ when student complies with direction, then he will receive an immediate break on the computer or in the play area Evidence $\rightarrow$ based on the results of the FBA; may also observe student engage with these activities

Frequency $\rightarrow$ every time; once 10 tokens are earned; after completing three activities

- Immediacy $\rightarrow$ break or token should be provided immediately Choice $\rightarrow$ choice of where to take break; activities to use during break

\section{Reactive strategies (p. 15)}

- Managing the problem behavior safely may entail providing sufficient space between student and classmates and rearranging the environment. For escapemaintained problem behavior it should not involve removal of demand (use broken-record prompting)

- May prompt student to use FERB (request a break)

- May redirect student back to task and remind the student of what they earn for finishing the task (break etc.)

- May involve debriefing after the student has completed the activity and is behaving appropriately (may not be appropriate for all students)

- Consequences or punishment based on school-wide policies or individual plan (not always necessary)

\section{Goals (p. 15): Guidelines on p. 21}

- Should identify FERB goal and respective goals to increase positive behavior and decrease problem behavior

"By 12/11, instead of engaging in self-injury (include definition), for the purposes of escaping gym class, Sally will complete 5 minutes of warm up without self-injury and then take a walk in the hallway to avoid the noise in gym class for at least $4 / 5$ gym class periods across 5 weeks. The frequency of self-injurious behavior and duration of time in gym class will be recorded by the instructional aid during gym class and graphed by Sally's teacher."

- Similar goals for increase/decrease behavior

\section{Progress monitoring (p. 17)}

-Who is responsible for ensuring plan is working?

- Needs to be clearly defined on lines 7,10 , $11,12,14$ 
Communication (p. 18): Guidelines on p. 22

- Specifies what information will be communicated about the FERB, increased appropriate behavior (if not the FERB), and decreases in problem behavior will be communication.

- Specifies what manner and how frequently this information will be communicated.

- Specifies how the receiving party will respond to communication. Must be two-way.

\section{-Let's practice!}

- If you have any questions about either training you participate in today please feel free to email me:

Aimee.Giles@mail.wvu.edu 
Appendix F

DRA Self-Monitoring Sheets

Targeted Appropriate Behavior:

\begin{tabular}{|l|l|l|}
\hline & Correct & Incorrect \\
\hline $\begin{array}{l}\text { Reinforcer delivered following each } \\
\text { instance of compliance (within } 10 \mathrm{~s} \text { ) }\end{array}$ & & \\
\hline Paired praise with break delivery & & \\
\hline
\end{tabular}

Target Problem Behavior:

\begin{tabular}{|l|l|l|}
\hline & Correct & Incorrect \\
\hline $\begin{array}{l}\text { Withhold break if problem behavior } \\
\text { paired with appropriate behavior. }\end{array}$ & & \\
\hline $\begin{array}{l}\text { Refrain from making a comment directly } \\
\text { about problem behavior }\end{array}$ & & \\
\hline $\begin{array}{l}\text { Ignore problem behavior during low } \\
\text { attention conditions }\end{array}$ & & \\
\hline $\begin{array}{l}\text { Continue with prompting student to } \\
\text { continue working if problem behavior } \\
\text { happens during a demand }\end{array}$ & & \\
\hline
\end{tabular}




\section{Appendix G}

TRP-15

\section{Training Rating Profile - (TRP-15)}

Please rate the training along the following dimensions. Please circle the number which best describes your agreement or disagreement with each statement.

1. The strategies I learned would be an acceptable way to deal with a child's problem behavior.

2. Most teachers would find the strategies described appropriate for behavior problems.

3. The strategies described should be effective in changing a child's problem behavior.

4. I would suggest that other teachers attend this training.

5. The training was applicable to issues in my classroom.

6. The trainers were well-prepared for the training session.

7. I would be willing to use the strategies that I learned in my classroom

8. The strategies I learned would not result in negative side-effects for the child.

9. The strategies I learned would be appropriate for a variety of children.

10. The trainers presented material in a clear and understandable way.

11. The trainers included an appropriate amount of interaction in the training.

12. The strategies I learned are "do-able" in a classroom environment.

13. I liked the procedures the procedures I learned about in this training.

14. The trainers allowed time for questions, and answered questions appropriately.

15. Overall, this training was beneficial for me as a teacher.

\begin{tabular}{|c|c|c|c|c|c|}
\hline 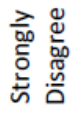 & 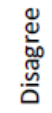 & 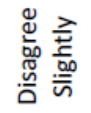 & 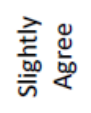 & 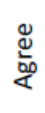 & 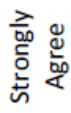 \\
\hline 1 & 2 & 3 & 4 & 5 & 6 \\
\hline 1 & 2 & 3 & 4 & 5 & 6 \\
\hline 1 & 2 & 3 & 4 & 5 & 6 \\
\hline 1 & 2 & 3 & 4 & 5 & 6 \\
\hline 1 & 2 & 3 & 4 & 5 & 6 \\
\hline 1 & 2 & 3 & 4 & 5 & 6 \\
\hline 1 & 2 & 3 & 4 & 5 & 6 \\
\hline 1 & 2 & 3 & 4 & 5 & 6 \\
\hline 1 & 2 & 3 & 4 & 5 & 6 \\
\hline 1 & 2 & 3 & 4 & 5 & 6 \\
\hline 1 & 2 & 3 & 4 & 5 & 6 \\
\hline 1 & 2 & 3 & 4 & 5 & 6 \\
\hline 1 & 2 & 3 & 4 & 5 & 6 \\
\hline 1 & 2 & 3 & 4 & 5 & 6 \\
\hline 1 & 2 & 3 & 4 & 5 & 6 \\
\hline
\end{tabular}

